\title{
Central Bank Communication That Works: Lessons from Lab Experiments
}

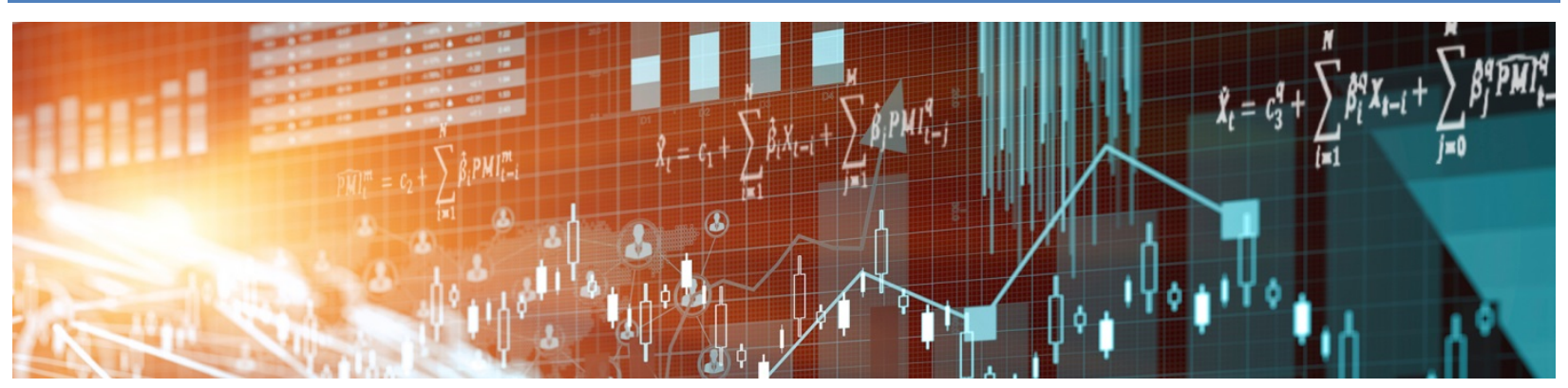

by Oleksiy Kryvtsov and Luba Petersen 
Bank of Canada Staff Working Paper 2019-21

June 2019

\title{
Central Bank Communication That Works: Lessons from Lab Experiments
}

by

Oleksiy Kryvtsov $^{1}$ and Luba Petersen ${ }^{2}$

\author{
${ }^{1}$ Economic and Financial Research \\ Bank of Canada \\ Ottawa, Ontario, Canada K1A 0G9 \\ okryvtsov@bank-banque-canada.ca \\ 2 Department of Economics \\ Simon Fraser University \\ Burnaby, British Columbia, Canada V5A 1S6 \\ luba_petersen@sfu.ca
}




\section{Acknowledgements}

We thank the editor, Ricardo Reis, and two anonymous referees for their comments and suggestions for rewriting the paper. We thank the Vancouver School of Economics for access to their experimental lab facilities. We are especially grateful to Jean Boivin for inspiring us to work on this project and for numerous helpful discussions. We thank Jasmina Arifovic, David Freeman, Cars Hommes, Jim MacGee, Amy Li, Isabelle Salle, Lanny Zrill, Sarah Zubairy for useful comments and suggestions. Minnie Cui provided superb research assistance, and Sherry Luo and Michael Mirdamadi provided excellent lab assistance. We thank Colette Stoeber for helpful editorial assistance. Finally, we thank the Bank of Canada and Social Science and Humanities Research Council of Canada for generous financial support. The views expressed here are ours, and they do not necessarily reflect the views of the Bank of Canada. All remaining errors are our own. 


\begin{abstract}
We use controlled laboratory experiments to test the causal effects of central bank communication on economic expectations and to distinguish the underlying mechanisms of those effects. In an experiment where subjects learn to forecast economic variables, we find that central bank communication has a stabilizing effect on individual and aggregate outcomes and that the size of the effect varies with the type of communication. Announcing past interest rate changes has the largest effect, reducing individual price and expenditure forecast volatility by one- and two-thirds, respectively; cutting half of inflation volatility; and improving price-level stability. Forward-looking announcements in the form of projections and forward guidance of upcoming rate decisions have less effect on individual forecasts, especially if they do not clarify the timing of future policy changes. Our evidence does not link the effects of communication to forecasters' ability to predict future nominal interest rates. Rather, communication is effective via simple and relatable backwardlooking announcements that exert strong influence on less-accurate forecasters. We conclude that increasing the accessibility of central bank information to the general public is a promising direction for improving central bank communication.
\end{abstract}

Bank topics: Monetary policy implementation; Transmission of monetary policy JEL codes: C9, D84, E3, E52

\title{
Résumé
}

Nous recourons à des expériences contrôlées de laboratoire pour évaluer l'influence des communications des banques centrales sur les attentes économiques et connaître les mécanismes sous-jacents qui facilitent cette influence. Les résultats d'une expérience dans le cadre de laquelle les sujets apprennent à prévoir l'évolution de variables économiques montrent que les communications des banques centrales ont un effet stabilisateur sur les prévisions individuelles et regroupées et que l'ampleur de cet effet varie en fonction du type de communication. Ainsi, les indications rétrospectives concernant les modifications du taux directeur produisent les effets les plus importants. Elles réduisent, respectivement de l'ordre d'un tiers et des deux tiers, la volatilité des prévisions individuelles quant aux prix et aux dépenses, font baisser de moitié la volatilité de l'inflation et renforcent la stabilité du niveau des prix. Les annonces prospectives qui se rapportent aux projections et aux indications fournies au sujet des décisions à venir sur la trajectoire du taux directeur ont moins d'incidence sur les projections individuelles, surtout si le moment où les modifications annoncées entreront en vigueur n'est pas précisé. Nos constatations 
n'établissent aucun lien entre les effets des communications et la capacité des sujets à prédire les taux d'intérêt nominaux. En revanche, les annonces rétrospectives claires et pertinentes qui ont une forte influence sur les prévisionnistes moins fiables prouvent l'utilité des communications. Pour les banques centrales, élargir l'accès du public à l'information qu'elles détiennent constitue une avenue prometteuse pour l'amélioration de leurs communications.

Sujets : Conduite de la politique monétaire; Transmission de la politique monétaire Codes JEL : C9, D84, E3, E52 


\section{Non-technical Summary}

Central bank communication has become a salient feature of monetary policy frameworks in the last few decades. Extremely low nominal interest rates and the need for continuing monetary stimuli since the Great Financial Crisis have led central banks to increase the scale and scope of their communication programs. Limited economic data, incomplete information about central banks' interest rate policies, ever-evolving communication strategies and the diversity of markets and market participants has made it extremely challenging to empirically assess the effectiveness of central bank communication.

To circumvent these challenges, we implement controlled laboratory experiments that systematically vary central bank communication. In our experiments, identification is based on experimental data generated under controls that are not available in economic data. Direct observation of the timing and magnitude of the shocks allows us to construct conditional responses. Heterogeneity across forecasters provides evidence on how expectations affect individual and aggregate outcomes. Knowledge of monetary policy rule and occasional monetary policy inaction helps to identify the exogenous components of interest rate changes. Finally, variation in the type of central bank announcements allows us to distinguish the mechanisms behind communication effects.

The overarching result in our experiments is that simpler, more accessible central bank communication tends to be more effective in influencing participants' forecasts. In our experiment, the best stabilization is achieved by central bank communication that relates to participants' recent experience. Stabilization benefits materialize even though the central bank's messages lack content about the future course of the economy. Rather, simplified and relatable announcements have especially strong impact on less-informed decision-makers.

Our findings support a cautious narrative for implications of forward-looking types of communication. We do not find any support for explicit communication of the path of nominal interest rates. Neither qualitative nor quantitative forward guidance yields substantial improvement in interest rate forecasts, which could be associated with the lack of clarity of the messaging or the lack of anchoring on the central bank's pronouncements.

The upshot of our paper is that the increase in accessibility of central bank information to the general public is a promising direction for improving the effectiveness of central bank communication. 


\section{Introduction}

Central bank communication has become a salient feature of monetary policy frameworks in the last few decades. Extremely low nominal interest rates and the need for continuing monetary stimuli since the Great Financial Crisis have led central banks to increase the scale and scope of their communication programs. A number of factors have made it extremely challenging to empirically assess the effectiveness of central bank communication. These include limited economic data, incomplete information about central banks' interest rate policies, ever-evolving communication strategies and the diversity of markets and market participants. ${ }^{1}$ To circumvent these challenges, we implement controlled laboratory experiments that systematically vary central bank communication. In our experiments, identification is based on experimental data generated under controls that are not available in economic data. Direct observation of the timing and magnitude of the shocks allows us to construct conditional responses. Heterogeneity across forecasters provides evidence on how expectations affect individual and aggregate outcomes. Knowledge of monetary policy rule and occasional monetary policy inaction helps to identify the exogenous components of interest rate changes. Finally, variation in the type of central bank announcements allows us to distinguish the mechanisms behind communication effects.

Our experimental framework is a learning-to-forecast (LTF) experiment based on an extended version of the Woodford (2013) model of heterogeneous expectations and monetary policy. In the model, households and firms make dynamic expenditure and price decisions based on their subjective expectations about future economic conditions and their own future decisions. In the LTF setup, participants ("subjects") provide incentivized period-by-period forecasts that are used as stand-ins for households' and firms' expectations. Experimental outcomes are computed sequentially based on these forecasts and the model's equilibrium equations. LTF experiments are an appealing experimental framework to study expectations without complications associated with suboptimal behavior (Bao, Duffy, and Hommes, 2013) and have has been used to study questions related to forecasting heuristics, asset pricing, and

\footnotetext{
${ }^{1}$ Blinder et al. (2008), Coenen et al. (2017), and Moessner, Jansen, and de Haan (2017) survey the literature on central bank communication.
} 
monetary policy (Marimon and Sunder, 1994; Adam, 2007; Hommes et al., 2008; Assenza et al., 2013; Pfajfar and Žakelj, 2016).

To study central bank communication, we extend this setup along two dimensions. First, we assume that occasionally the automated central bank in our experiment keeps its interest rate unchanged. Zero interest rate changes are common in the data: they accompany a share of fixed-date monetary policy announcements of major central banks. ${ }^{2}$ Central banks can disburse information with and without interest rate changes, which underscores the role of central bank communication as an independent tool of monetary policy. Moreover, in the absence of interest rate changes, e.g., when they are constrained by the zero lower bound, the public's attention is drawn to central bank announcements, potentially amplifying their influence. For simplicity, we assume that the timing of inaction is random and exogenous, which gives us an additional source of exogenous variation for identifying the effects of central bank communication.

Second, we add monetary policy communication in the form of occasional announcements by a monetary authority. We explore three different types of central bank communication that major central banks have pursued to bolster the impact of monetary policy. In the COM-BACK treatment, the central bank announces the direction of the central bank's past interest rate action. This information helps participants better understand how monetary policy responds to the recent state of the economy. In the COM-FWD treatment, the central bank announces its expected rate change in the upcoming period based on current and expected economic fundamentals. This treatment helps investigate how forward guidance that is short-term and state-contingent can influence expectation formation. Finally, in the COM-COMMIT treatment, during monetary policy inaction, the central bank announces the number of periods before the next rate change. This treatment captures the effects of time-dependent forward guidance and minimal policy uncertainty. We identify the effects of communication through econometric analysis of the differences between the control experiment (no communication) and each of the treatments.

\footnotetext{
${ }^{2}$ Based on the data from BIS on central bank policy rates, the fraction of quarters with zero quarter-toquarter interest rate changes is 0.59 in the United States, 0.58 in the United Kingdom, 0.44 in Canada, 0.80 in Japan (all for the period 1993Q1-2017Q4), and 0.57 in Euro Area (1999Q1-2017Q4).
} 
Overall, the dynamics in our experiments demonstrate clear links between information constraints faced by forecasters and monetary policy. In the control experiment, the responses of forecast errors to demand and monetary policy shocks are large and persistent, suggesting that participants do not fully utilize information that is relevant for their forecasts. Consequently, aggregate outcomes exhibit volatility and persistence that are substantially greater than predicted under full-information rational expectations (FIRE). On rare occasions, we observe extreme fluctuations in output and inflation. Such evidence is typical for lab experiments and surveys of households or firms, and it has served as the basis for ruling out FIRE (Nagel, 1995; Coibion and Gorodnichenko, 2012). Nonetheless, we find that in response to unexpected interest rate changes, forecasts respond in the same direction as FIRE forecasts, indicating that subjects qualitatively understand the impact of interest rate changes on the variables they forecast. Altogether, laboratory outcomes reflect information constraints and behavioral tendencies that are directly relevant for studying central bank communication.

We find that central bank communication has a stabilizing influence on individual forecasts. In all COM treatments, forecast responses are more muted after a demand shock, and the associated forecast errors are smaller. Quantitatively, COM-BACK treatment has the largest effect, reducing individual price and expenditure forecast response by about one-third and two-thirds, respectively. The associated forecast errors decrease by a quarter for prices and almost entirely for expenditures. Interest rate forecasts are also significantly muted. The effects of FWD and COMMIT communication are smaller than BACK effects by about a half and are less significant.

The stabilization benefits of COM-BACK materialize even though it provides no content about the future course of the economy. The relative improvements in price and expenditure forecasting in COM-BACK are not associated with improvements in interest rate forecasts. Rather, BACK communication is effective because it is simple and relatable. When we dissect responses by subjects' forecasting ability, communication has the largest effects on the lessaccurate forecasters. For the bottom half of forecasters, price (expenditure) forecasts after a demand shock are reduced by a half (completely) in COM-BACK treatment and by almost 
one half (two-thirds) in COM-FWD and COM-COMMIT treatments. Treatment effects for the top half of forecasters are not significantly different from zero in all experiments. The reduction in forecast volatility after demand shocks is also in part because COM makes interest rates more salient to participants. For example, forecast responses for prices and expenditures become more sensitive to monetary surprises in COM treatments, especially in COM-BACK treatment.

Communication stabilizes aggregate responses, and its effects increase with the response horizon, indicating that the stabilization benefits accrue over time. Quantitatively, the largest stabilization occurs in COM-BACK treatment where the cumulative inflation response after 10 periods following the demand shock is half that of the control experiment. COM-COMMIT delivers a similar reduction in inflation but it also comes with a persistent decrease in output, whereas output rebounds in COM-BACK treatment. Treatment effects for COM-BACK and COM-COMMIT almost double when we account for the endogenous countercyclical response of interest rates. Treatment effects are the smallest and statistically insignificant in COM-FWD treatment.

Our results suggest that stabilization benefits can be achieved by effective communication even without the change in interest rate policy. In COM-BACK and, to a lesser extent, in COM-COMMIT treatments the response of inflation to an expansionary demand or monetary policy shock undershoots the target along the adjustment path, implying better price-level stability. That is because communication stabilizes individual expenditure forecasts more effectively than it does price forecasts. In the model, expenditures depend on the expected future path of interest rates, whereas prices depend on expected interest rates only via expectations of the future output gap. Since subjects cannot perfectly distill the indirect effect on prices - as in the FIRE model - the stabilizing impact of communication on expenditures is greater than on prices. When output falls quickly after a positive demand shock, it puts downward pressure on the price level. Previous work has emphasized how the pursuit of price-level targeting may yield stabilization benefits relative to inflation targeting because of additional stabilization of inflation expectations (Vestin, 2006).

Our key takeaway is that central bank communication based on simple and relatable in- 
formation can be more effective than complex messaging. Central banks are exploring ways to make their communication more accessible to a wider public by using simple language, visualization, and social media. Coibion et al. (2018) argue that such new communication strategies are promising for lifting the "veil of inattention" of households and firms to monetary policy announcements in low-inflation economies. Bholat et al. (2018) find that visualized and relatable information in the summary of the Bank of England's Inflation Report improve public comprehension and trust. We provide evidence that the benefits of communication emerge mainly from its ability to anchor less-informed participants' expectations.

We show that the complexity of the messaging is a factor for both FWD and COMMIT communication in our experiments, as neither type of guidance yields improvement in interest rate forecasts. Existing evidence on the effectiveness of forward-guidance policies is at best mixed. Campbell et al. (2017) explain that when the communication of central banks fails to distinguish the assessment of economic outlook from the projection of future interest rate responses, forward-guidance stabilization is limited. Jain and Sutherland (2018) find that while interest rate projections and forward guidance reduce disagreement about upcoming rate decisions, they have little impact on macroeconomic forecasts. Ehrmann et al. (2019) show that even time-contingent forward guidance can increase interest rate responsiveness to macroeconomic news. We report evidence of central bank communication providing focal points for participants' expectations by explicitly referencing the past (BACK) or future (COMMIT) interest rates. Hence, anchoring expectations offsets the complexity of timedependent forward guidance for experiment participants. By contrast, qualitative guidance (FWD) is less effective for managing the expectations of less-accurate participants, likely because it provides no explicit focal points.

While the literature mostly studies the impact of central bank announcements on financial markets and professional forecasters, a growing literature has provided empirical evidence for households and non-financial firms. These studies explore a variety of methods to identify the effects of central bank communication using randomized treatments in surveys and field experiments (Haldane and McMahon, 2018, Coibion, Gorodnichenko, and Weber, 2019), textual analysis (Bholat, Hans, Santos, and Schonhardt-Bailey, 2015), and 
high-frequency identification (Lamla and Vinogradov, 2019). LTF experiments complement these approaches by basing identification on experimental data generated under controls that are not available in economic data.

Related experiments have explored communication in conjunction with conventional policy options, such as inflation targets under single and dual mandates (Cornand and M'baye, 2018) and time-varying inflation targets at the zero lower bound (Arifovic and Petersen, 2017). Others have studied how macroeconomic forecasts can be managed through various types of central bank projections (Mokhtarzadeh and Petersen, 2017) and macroeconomic literacy training (Mirdamadi and Petersen, 2018). We add to this literature by incorporating different types of central bank communication directly into the design and testing their respective effects on individual and aggregate outcomes.

In what follows, Section 2 lays out the elements of our experimental framework: model, procedures, treatments, and interface. Section 3 explains the econometric analysis of experimental outcomes and presents the dynamics in the control experiment. Section 4 provides the estimated treatment effects of central bank communication. Section 5 contains a broad discussion of the paper's findings and offers conclusions.

\section{Experimental Framework}

Our framework is a learning-to-forecast (LTF) experiment based on an extended version of Woodford's (2013) model of heterogeneous expectations and monetary policy. The New Keynesian model with heterogeneous expectations was first introduced in the lab by Mauersberger (2017). In the LTF setup, participants provide incentivized period-by-period forecasts that are used as stand-ins for households' and firms' expectations. Experimental outcomes are computed sequentially based on these forecasts and the model's equilibrium equations. ${ }^{3}$ The next section provides a brief overview of the model.

\footnotetext{
${ }^{3}$ Our motivation for focusing only on expectation formation stems from the general view that central bank communication is thought to influence the economy primarily through its effect on expectations. Alternative frameworks to elicit expectations in include individual choice and production economy experiments (Bao, Duffy, and Hommes, 2013; Noussair, Pfajfar, and Zsiros, 2015; Petersen, 2015).
} 


\section{$2.1 \quad$ Model}

The demand side is derived from the optimization problem of a large number of infinitelylived ex-ante identical households who maximize expected discounted utility by choosing sequences of consumption and hours worked while forming subjective expectations about the future stream of income and the rate of return on savings. Households trade a riskfree nominal one-period government debt. They choose hours worked which are demanded by firms at the wage set by labor unions on households' behalf. The consumption expenditure problem is fairly standard, except expectations are subjective and specific to the household. Under the assumption that taxes and public debt have no direct influence on households' expectations, log-linear approximation of consumption expenditures for household $i$ can be characterized by the evolution of individual state variables $\left\{\bar{v}_{i t}\right\}$, given by the following recursive equation: ${ }^{4}$

$$
\bar{v}_{i t}=(1-\beta) \sum_{i} \bar{v}_{i t}-\beta \sigma\left(i_{t}-\pi_{t}\right)+\beta E_{i t} \bar{v}_{i t+1},
$$

where all variables are $\log$ deviations from a deterministic steady state, $i_{t}$ is nominal interest rate, $\pi_{t}$ is inflation rate, and $E_{i t}(\cdot)$ denotes household $i$ 's subjective expected value in period $t$. The expectational variable $\bar{v}_{i t}$ summarizes joint evolution of household $i$ 's expected flow of total expenditures over time based on their future forecasts. ${ }^{5}$ In our experiments, for simplicity, we refer to $\bar{v}_{i t}$ as "expenditures."

This specification of the household's problem makes two important deviations from standard models with full-information rational expectations, demonstrated convincingly in Preston (2005). First, the expectational variable $\bar{v}_{i t}$ reflects expectations many periods into the future. Second, individual expectations cannot be directly aggregated into expectations of a

\footnotetext{
${ }^{4}$ Some of the assumptions required for the Ricardian expectations or log-linear approximation may not always hold in the experiment. For example, expectation errors are not always small and fluctuations may be explosive. We primarily focus on non-explosive experimental outcomes, leaving these issues for future research. See Woodford (2013) for a detailed discussion of the assumptions in the model.

${ }^{5}$ Individual consumption, $c_{i t}$, is a function of the subjective future expected value of $\bar{v}_{i t}$; individual debt holdings, $b_{i t}$; aggregate output less tax revenue, $y_{t}-\tau_{t}$; deviations of the real interest rate from the rate of time preference, $\beta i_{t}-\pi_{t+1}$; income from government debt, $s_{b}\left(\beta i_{t}-\pi_{t}\right)$; and preference shocks to consumption, $\bar{c}_{t}: c_{i t}=(1-\beta) b_{i t}+(1-\beta)\left(y_{T}-\tau_{t}\right)-\beta\left(\sigma-(1-\beta) s_{b}\right) i_{t}-(1-\beta) s_{b} \pi_{t}+\beta \bar{c}_{t}+\beta E_{i t} \bar{v}_{i t+1}$.
} 
"representative agent." 6

Aggregate demand is given by

$$
y_{t}-r_{t}^{n}+\sigma \pi_{t}=\sum_{i} \bar{v}_{i t}
$$

where $y_{t}$ is the log deviation of aggregate output from the steady state, and $r_{t}^{n}$ is an exogenous "demand shock," associated, for example, with a shock to government purchases or to the marginal utility of consumption. We assume that $r_{t}^{n}$ follows an $\mathrm{AR}(1)$ process, $r_{t+1}^{n}=$ $\rho_{r} r_{t}^{n}+\epsilon_{t+1}$, with i.i.d. innovations $\epsilon_{t} \sim N\left(0, \sigma_{r}^{2}\right)$.

Aggregate supply is based on optimization by a large number of monopolistically competitive firms. With probability $\alpha$ the firm's price will remain unchanged from the previous period. With probability $1-\alpha$ the firm $j$ can set its price to a level $p_{j t}^{*}$, which satisfies

$$
p_{j t}^{*}=(1-\alpha) \sum_{j} p_{j t}^{*}+(1-\alpha \beta) \zeta y_{t}+\alpha \beta E_{j t} p_{j t+1}^{*},
$$

where $\zeta$ is the degree of real rigidity, $y_{t}$ is the output gap ${ }^{7}$ and where inflation is

$$
\pi_{t}=(1-\alpha) \sum_{j} p_{j t}^{*}
$$

Finally, the interest rate policy is determined by a Taylor rule with a possibility of inaction. Monetary policy inaction is determined by the realization of the i.i.d. Poisson random variable $\mathcal{I}_{t}$ taking on values of 1 with arrival rate $\iota$, and 0 otherwise. When the random variable is 1 , the interest rate in $t$ is determined by the Taylor rule, with the interest rate responding to deviations of inflation from the zero inflation target and output gap, and

\footnotetext{
${ }^{6}$ Preston (2005) explains how these deviations can lead to important implications for the stability of learning dynamics.

${ }^{7}$ In this simple setup, we are abstracting from model features that drive a wedge between output gap and aggregate output deviations from its steady state (e.g., exogenous variations in firms' desired price markup). In the text, we use "output," "output deviation," and "output gap" interchangeably.
} 
otherwise the interest rate is equal to the interest rate in $t-1$ :

$$
i_{t}= \begin{cases}\phi_{\pi} \pi_{t}+\phi_{y} y_{t} & \text { w.p. } \iota \\ i_{t-1} & \text { w.p. } 1-\iota .\end{cases}
$$

Interest rate inaction plays an important role in our framework. First, inaction is motivated by the fact that roughly half of monetary policy announcements by major central banks are accompanied by zero interest rate change. Furthermore, central banks communicate their views both at the time of announcements and between announcements. Therefore, the assumption of inaction captures the role of central bank communication as an independent tool of monetary policy. Finally, in the model, random timing of inaction leads to monetary policy surprises, which we use as an additional source of exogenous variation for identifying the effects of central bank communication. ${ }^{8}$

The model is closed by specification of processes for subjective expectations $\left\{E_{i t} \bar{v}_{i t+1}\right\}$ and $\left\{E_{j t} p_{j t+1}^{*}\right\}$. When expectations are full-information rational, the model is a standard New Keynesian DSGE model akin to Clarida, Galí, and Gertler (1999). In a general case of independently specified expectations, Woodford (2013) demonstrates that a concept of "temporary equilibrium" can be applied where subjective expectations are consistent with equilibrium dynamics.

\subsection{Experimental implementation}

In the LTF experiment, expectations are supplied period-by-period by experiment participants, who provide a forecast for one household's expenditure and one firm's price. The sequential unraveling of information in the LTF experiment imposes timing restrictions on experimental decisions and outcomes. When making their forecast decisions in period $t$, subjects do not observe endogenous variables for that period because those variables depend

\footnotetext{
${ }^{8}$ The assumption of random timing of action excludes an option for monetary policy in the model to accelerate or delay interest rate changes to stabilize the economy. This assumption is akin to implications of the zero lower bound (ZLB) on monetary policy. Since we use the assumption for identification of communication effects, we abstract from endogenous timing of monetary policy actions. Arifovic and Petersen (2017), Hommes, Massaro, and Salle (2019) study monetary policy inaction at the ZLB.
} 
on period- $t$ forecasts (see, for example, equation 1 for $\bar{v}_{i t}$ ). Intuitively, each period is divided in two sub-periods: before forecasting decision ("morning") and after ("evening") (see Figure E.3 in Supplementary Material).

In the morning of period $t$, subject $i$ observes the realization of the demand shock, $\epsilon_{t}$; central bank communication, if any, $C O M_{t}$; realizations of monetary policy inaction in the evening of period $t-1, \mathcal{I}_{t-1}$; individual price and expenditure variables in period $t-1$, denoted by $X_{i t-1}$; inflation and output in period $t-1$, denoted by $X_{t-1}$; and the nominal interest rate $i_{t-1}$. Subject $i$ then submits her subjective forecasts for price and expenditure in period $t+1, E_{i t}\left(X_{i t+1}\right)$, and for interest rate in period $t+1, E_{i t}\left(i_{t+1}\right)$. After all forecasts are submitted, i.e., in the evening of period $t$, monetary policy inaction in period $t$ is realized, $\mathcal{I}_{t}$, and individual prices and expenditures, aggregate output, inflation, and interest rate in period $t$ are determined, according to equations (1)-(5).

We choose parameter values that allow the model to replicate salient features of inflation and output-gap fluctuations in Canada between 1993Q1 and 2017Q4. In our calibration exercise we use a version of the model with adaptive expectations (see Section D in Supplementary Material), although assuming rational expectations does not substantially alter the model's fit to the data. Standard deviation and serial correlation of the demand shock process $\left(\sigma_{r}\right.$ and $\left.\rho_{r}\right)$, the degree of real rigidities $(\zeta)$, and Taylor rule inflation parameter $\left(\phi_{\pi}\right)$ are calibrated to match the following four moments in the Canadian data: standard deviation and serial correlation of inflation deviations ( 0.54 per cent and 0.4 , respectively), the ratio of standard deviations of the output gap and inflation (2.1), and the ratio of standard deviations of the nominal interest rate and inflation (1).

This gives us $\sigma_{r}=0.012, \rho_{r}=0.45, \zeta=0.8$, and $\phi_{\pi}=1.4$. The fraction of quarters with non-zero quarterly change in nominal interest rate is 0.56 , which pins down the frequency of monetary policy action $\iota .{ }^{9}$ The remaining parameters are assigned values commonly used in

\footnotetext{
${ }^{9}$ Central banks may choose not to adjust their policy rates because of a lack of change in economic activity and inflation, central bank uncertainty resulting in a "wait-and-see" approach, competing objectives, or the presence of an effective lower bound. Over the past decade, many OECD countries have experienced more monetary policy inaction than action. Central banks have been keeping their policy rates unchanged for unprecedentedly long periods. E.g., as of February 2019, Australia has held its policy rate constant at 1.5\% for 30 consecutive months despite room to move lower. The Bank of England held its official bank rate constant for over seven years from March 2009 to July 2016. The ECB has also kept its policy rates steady
} 
the literature: the discount factor, $\beta$, is $0.96^{1 / 4}$; intertemporal elasticity of substitution, $\sigma$, is one; quarterly probability of price adjustment, $1-\alpha$, is 0.49 (or 0.20 at monthly frequency), and the Taylor-rule coefficient on the output gap is 0.07 .

\subsection{Procedures}

The experiment was conducted at the Vancouver School of Economics' Experimental Economics Laboratory in British Columbia. The subject pool consisted of undergraduate participants, who have, as a general population, been shown to be well-incentivized by monetary rewards and whose forecasting behavior is consistent on many dimensions with professional forecasters, households, and firms (Cornand and Hubert, 2018). Subjects with no experience in LTF experiments were invited to participate in sessions that involved 30 minutes of instruction and 90 minutes of game participation. Each session involved seven subjects interacting together in a single group.

In LTF experiments, the participants' only task is to form expectations about future economic variables, and their decisions are automated according to a data-generating process presented above. At the beginning of the experiment, subjects were provided with detailed verbal and paper instructions, and explained their roles and payoffs (Section A in Supplementary Material). Instructions contained qualitative and quantitative information about households' and firms' decisions, and the automated central bank's reaction function. In particular, we informed participants that the central bank would respond to deviations of inflation and output gap from target, and that the central bank would react more than one-for-one with inflation. Subjects served as professional forecasters for their designated households and firms (one household and one firm per participant), and were also asked to forecast the nominal interest rate. Each period, before making their new forecasts, participants observed the complete history of past forecasts and realizations of the nominal interest, their own prices and expenditures, as well as realizations of inflation, output, and the concurrent demand shock. After forecasts were submitted in basis points (bps), outcomes were

for more than three years from 2016 to 2019 . Likewise, Denmark has kept its rates constant at $-0.65 \%$ since early 2016 . 
computed using the model in Section 2.1. For aggregate expectations we used median, rather than mean, forecasts to reduce influence of individual entries on aggregate outcomes.

Participants were remunerated based on their forecast accuracy. Subject $i$ 's accuracy score $S_{i t}$ in period $t$ was determined by the following function of their own absolute forecast errors:

$$
S_{i t}=0.33\left(2^{-0.01\left|p_{i t}-E_{i t-1} p_{i t}\right|}+2^{-0.01\left|\bar{v}_{i t}-E_{i t-1} \bar{v}_{i t}\right|}+2^{-0.01\left|i_{t}-E_{i t-1} i_{t}\right|}\right),
$$

where $E_{i t-1} X_{i t}$ is subject $i$ 's forecast in period $t-1$ for variable $X_{i t}$. At the end of the experiment, each participant's total score $\sum_{t} S_{i t}$ was translated into cash remuneration at an exchange rate of 1 point $=\mathrm{CDN}$ 0.75. A subject could earn a maximum of 69 points, or $\$ 51.75$, if they made accurate forecasts. Such scoring rules incentivize participants to make accurate forecasts: for every additional error of 100 bps for each of their three forecasts, the subjects' score in that period would decrease by half.

Each experimental session consisted of four practice periods before the 70-period experiment, with both phases initialized at the steady state. Periods lasted for 75 seconds for the first nine periods and 60 seconds thereafter. An additional five-second warning was given if a subject had not submitted her forecast on time before continuing onto the next period. In all, $99.2 \%$ of forecasts were submitted on time. Earnings, including a $\$ 10$ fee for showing up on time, ranged from $\$ 15$ to $\$ 43$ and averaged $\$ 32$ for two hours.

Our experimental framework offers appealing features for studying the effects of communication on expectations. Shocks are Gaussian, and the number of time observations per forecaster is greater than in surveys of forecasters. These features help reduce econometric challenges associated with the use of forecaster-level data, such as measurement errors, sample bias, or extreme shocks (Pesaran and Weale, 2006). Furthermore, both the datagenerating process and participants' accuracy scores are symmetric around zero, which diminishes the scope for alternative interpretations of individual expectations formation, such as heterogeneity in loss aversion (Capistrán and Timmermann, 2009) and forecast smoothing (Croushore, 1997). And since participants' forecasts are private and aggregate variables are based on the medians, the incentives for strategic behavior are limited (Ottaviani and 
Sørensen, 2006).

\subsection{Treatments}

In the control experiment, there is no central bank communication. The remaining three treatments introduce different types of central bank communication in the form of occasional announcements to all subjects. During the instruction phase subjects are informed about the conditions under which the announcements are made.

In COM-BACK treatment, subjects receive central bank announcements about the previous period interest rate changes. The announcement states "The interest rate increased last period" or "The interest rate decreased last period," and there is no announcement if the interest rate has not changed, or if the change is smaller than 25 bps in magnitude (16\% of all non-zero changes). Backward-looking announcements are intended to improve transparency and help participants better understand how monetary policy responds to recent developments in the economy. Information on all past interest rates is available on the screen throughout the experiment, and so a COM-BACK announcement does not provide information that was not previously available.

In COM-FWD treatment, all subjects receive announcements about the central bank's expected policy decision in the evening. The announcement stated "The interest rate will likely increase this period" or "The interest rate will likely decrease this period," and there is no announcement if the interest rate is expected to stay within 25 bps from zero. Subjects are informed the announcement is based on the central bank's period- $(t-1)$ forecast of the period $t$ interest rate given by ${ }^{10}$

$$
E_{t-1}^{C B} i_{t}=0.007+0.317 i_{t-1}+0.084 r_{t-1}^{n} .
$$

If $E_{t-1}^{C B} i_{t}$ exceeded (fell short of) $i_{t-1}$ by more than $25 \mathrm{bps}$, the central bank would announce that the interest rate was likely to increase (decrease) this period. In contrast to COM-

\footnotetext{
${ }^{10}$ The central bank's forecast is the predicted value of the OLS regression for $i_{t}$ on $i_{t-1}$ and $r_{t-1}^{n}$ using model simulations under adaptive expectations.
} 
BACK treatment, the announcement in COM-FWD treatment is informative about how interest rates will respond to economic developments later in period $t$ and thereafter. This treatment, therefore, explores how short-term qualitative forward guidance can influence expectation formation.

In the COM-COMMIT treatment, subjects are informed that, occasionally, the nominal interest rate will stay unchanged, and during those periods, the central bank will announce the number of periods before the next change. At the end of these periods of inaction, the central bank announces that the interest rate will change in the current period. For example, an announcement in Period 10 that "The interest rate will remain unchanged for 3 periods" means that the interest rate will stay constant at its Period 9 level until Period 12. In Period 11, subjects receive a message, "The interest rate will stay unchanged for 2 periods." In Period 12, the announcement states "The interest rate will change in the next period." Finally, in Period 13, the message states "The interest rate will change this period." This treatment captures the effects of time-dependent forward guidance, and it significantly reduces uncertainty about the future path of interest rates.

Each treatment consisted of eight independent sessions with a total of 224 inexperienced participants. Each session within a treatment was based on randomly selected 70-period sequences of demand shocks $r_{t}^{n}$ and monetary policy action shocks $\mathcal{I}_{t}$. To facilitate comparisons across treatments, we employed identical shock sequences in all treatments. Section B in Supplementary Material provides details of experimental interface.

\section{Unconditional and Conditional Responses in Control Treatment}

This section begins with a summary of unconditional moments for experimental outcomes. We then explain how conditional responses are estimated and report these responses in the control treatment. 


\subsection{Summary of experiments}

Across experimental sessions, there is rich variation in individual forecasts, both across subjects and over time for each subject. These behaviors lead to a wide range of inflation and output dynamics, providing useful data for studying the effects of monetary policy and its communication. For the most part, inflation, output, and interest rates exhibit stable cyclical behavior; Section H in Supplementary Material provides time series for all four treatments. ${ }^{11}$

Table 1 provides descriptive statistics for experimental outcomes. Panel A provides standard deviations of forecasts and forecast errors for individual price $\left(p_{j t}^{*}\right)$, individual expenditure $\left(\bar{v}_{i t}\right)$, and interest rate $\left(i_{t}\right)$, expressed relative to standard deviations of respective forecast variables. Forecast errors are computed as $X_{i t}-E_{i t-1} X_{i t}$, with negative values indicating that participant $i$ over-forecasts a positive-valued variable, and vice versa. In the FIRE model, forecasts are much less volatile than forecasted variables, with relative standard deviations of $0.21,0.62$, and 0.49 for price, expenditure, and interest rate, respectively. Subjects' forecasts and forecast errors are more volatile and persistent relative to full-information rational forecasts and forecast errors, suggesting that subjects face substantial information constraints or limited capacity for processing information. By design, both demand and monetary action shocks are common for all subjects, and therefore, if heterogeneity in information processing is not very large, individual and aggregate variables should exhibit similar volatility. In the experiments, individual prices and especially expenditures are more volatile than their aggregates, by a factor between 1.09 and 1.13 for price and between 2.54 and 4.32 for expenditures. ${ }^{12}$

Panel B provides standard deviations for inflation, output, and interest rate, and the fractions of their variance explained by demand shocks and monetary policy surprises. Like individual variables, aggregate variables are more volatile in the experiment than in the FIRE

\footnotetext{
${ }^{11}$ Occasionally, there are episodes with explosive aggregate outcomes defined as periods for which the absolute value of inflation or interest rate exceeds 10 times the standard deviation of the demand shock (1344 bps), or the absolute value of output gap exceeds 20 standard deviations of the shock (2688 bps). For econometric analysis of stable dynamics, we exclude explosive episodes and two periods before and after each episode to dismiss transition to and from explosive episodes. Section I in Supplementary Material analyzes explosive dynamics.

${ }^{12}$ Excessive volatility of individual forecasts is well-documented in LTF literature, especially in heterogeneous expectations environments (Pfajfar and Žakelj, 2016; Mauersberger, 2017).
} 
model. Demand shocks drive most of the time series variation. In the FIRE model, demand shocks account for $0.95,0.92$ and 0.70 of the variance of inflation, output, and interest rate, respectively, with the remaining fraction due to unexpected changes in interest rates. In the experiments, monetary policy surprises are more important than in the FIRE model; in the following section, we present evidence that this is due to increased influence of monetary policy changes on forecasts in the presence of central bank communication.

Unconditional statistics in Table 1 (columns 3-5) suggest that central bank communication is associated with differences in the volatilities of individual and aggregate variables across treatment experiments. Nonetheless, drawing inference about the effects of communication based only on unconditional moments is complicated due to (i) aggregation of each subject's responses to different shocks, (ii) aggregation of responses across subjects, and (iii) countercyclical responses of interest rates. Our experimental design allows us to address these issues. Since the shocks are observed, we identify and estimate experimental outcomes conditional on demand shocks and monetary policy surprises. We then test whether these conditional moments are affected by central bank communication.

\subsection{Estimation of conditional responses to shocks}

The advantage of the experimental framework is that the exogenous processes for shock $r_{t}^{n}$ and monetary policy action $\mathcal{I}_{t}$ are observed by the experimenter. This allows us to estimate the dynamics of the endogenous variables as functions of the sequences of $r_{t}^{n}$ and $\mathcal{I}_{t}$, subject to information constraints explained Section 2.1. We first estimate conditional outcomes in the control experiment (no communication). The dynamics of individual $i$ 's forecasts for variable $X_{i t+1}$ are estimated with the following empirical specification:

$$
\begin{aligned}
E_{i t} X_{i t+1} & =c_{0}+c_{01} \mathcal{I}_{t-1}+\left(c_{1}+c_{11} \mathcal{I}_{t-1}\right) E_{i t-1} X_{i t}+\left(c_{2}+c_{21} \mathcal{I}_{t-1}\right) E_{i t-2} X_{i t-1} \\
& +\left(c_{3}+c_{31} \mathcal{I}_{t-1}\right) \epsilon_{t}+\left(c_{4}+c_{41} \mathcal{I}_{t-1}\right) \epsilon_{t-1}+\left(c_{5}+c_{51} \mathcal{I}_{t-1}\right) r_{t-2}^{n}+D_{s}+\text { error } \text { r }_{i t}
\end{aligned}
$$

Specification (6) conditions on the past two individual forecasts, the history of shocks, summarized by $\epsilon_{t}, \epsilon_{t-1}$, and $r_{t-2}^{n}$, and session dummy $D_{s}$. Each independent variable on the 
right-hand side is interacted with the indicator of whether policy acted last period, $\mathcal{I}_{t-1}$. Equation (6) is estimated independently for each variable $X_{i t}$ by a random-effects GLS regression and Huber-White robust standard errors. To exclude outliers, observations for explosive episodes and all observations for subjects ranked 7 are excluded; forecasts are then winsorized at the 2nd and 98th percentile.

For estimating the dynamics of individual variables $X_{i t}$ we use the same specification, except we replace $\mathcal{I}_{t-1}$ with $\mathcal{I}_{t}$ to reflect the fact that they are determined upon realization of monetary policy inaction variable in period $t$ :

$$
\begin{aligned}
X_{i t} & =c_{0}+c_{01} \mathcal{I}_{t}+\left(c_{1}+c_{11} \mathcal{I}_{t}\right) X_{i t-1}+\left(c_{2}+c_{21} \mathcal{I}_{t}\right) X_{i t-2} \\
& +\left(c_{3}+c_{31} \mathcal{I}_{t}\right) \epsilon_{t}+\left(c_{4}+c_{41} \mathcal{I}_{t}\right) \epsilon_{t-1}+\left(c_{5}+c_{51} \mathcal{I}_{t}\right) r_{t-2}^{n}+D_{s}+\text { error }_{i t} .
\end{aligned}
$$

Similar specification is used to estimate the dynamics of aggregate variables, $X_{t}\left(X_{i t}\right.$ replaced with $X_{t}$ in equation 7). Time series dynamics are estimated using OLS regression with session fixed effects and robust standard errors. ${ }^{13}$

We use the estimated systems to construct impulse response functions for the demand impulse $\epsilon_{t}$ and for monetary policy surprises. Monetary policy surprises are associated with the realization of monetary policy action or inaction in each period. Let $E_{i t}^{0}(\cdot)$ denote the expected value with respect to information available through the morning of period $t$. A monetary policy surprise in period $t$ is defined as deviations of the inaction dummy $\mathcal{I}_{t}$ relative to its stochastic steady state: $\Delta \mathcal{I}_{t}=\mathcal{I}_{t}-E_{i t}^{0}\left(\mathcal{I}_{t}\right)=\mathcal{I}_{t}-\rho_{i}$. Since $\mathcal{I}_{t}$ are i.i.d., monetary policy surprises are uncorrelated with $\epsilon_{t}$ at all leads and lags. Impulse response functions (IRFs) for demand shock are constructed keeping monetary policy surprises at zero. In general, IRFs for monetary surprises depend on the endogenous response of the economy to past demand shocks. To control for the history leading up to the monetary surprise, we normalize these IRFs with the same history we used for IRFs to the demand impulse. Intuitively, an IRF for an expansionary monetary surprise provides the additional response

\footnotetext{
${ }^{13}$ The results are generally robust to including additional lags for independent variables and to duplicating excluded observations across all treatments (instead of excluding them treatment-by-treatment).
} 
to a positive demand impulse that is due to a monetary policy inaction in the period of the impulse. IRFs for monetary surprises are useful for assessing how participants respond to unanticipated monetary policy action or inaction. ${ }^{14}$

Finally, IRFs for forecast errors cannot be estimated directly using specification (7) as it does not incorporate different measurability restrictions for $X_{i t}$ and $E_{i t-1} X_{i t}$. Instead, the IRFs for forecast errors are constructed by differencing the estimated IRFs for $X_{i t}$ and $E_{i t-1} X_{i t}$. Section $\mathrm{F}$ in Supplementary Material provides details for how all IRFs are constructed.

To estimate the effects of communication, we expand the baseline specification (6) with additional terms that include communication dummy $\Gamma_{T}$, taking on zero values for observations from the control experiment and unit values for observations in one of the three treatments, $T \in\{\mathrm{COM}-\mathrm{BACK}, \mathrm{COM}-\mathrm{FWD}, \mathrm{COM}-\mathrm{COMMIT}\}:$

$$
\begin{aligned}
E_{i t} X_{i t+1} & =\left[1, E_{i t-1} X_{i t}, E_{i t-2} X_{i t-1}, \epsilon_{t}, \epsilon_{t-1}, r_{t-2}^{n}\right]\left(\mathbf{c}_{\mathbf{r}}+\mathbf{c}_{\mathbf{r} 1} \mathcal{I}_{t-1}\right) \\
& +\left[1, E_{i t-1} X_{i t}, E_{i t-2} X_{i t-1}, \epsilon_{t}, \epsilon_{t-1}, r_{t-2}^{n}\right]\left(\mathbf{c}_{\mathbf{r} 2}+\mathbf{c}_{\mathbf{r} 3} \mathcal{I}_{t-1}\right) \Gamma_{T}+D_{s}+\text { error }_{i t} .
\end{aligned}
$$

The first term on the right-hand side is a shorter notation for the right-hand side in (6), with $(6 \times 1)$ column vectors $\mathbf{c}_{\mathbf{r}}$ and $\mathbf{c}_{\mathbf{r} 1}$ containing regression coefficients, and the second term containing the same terms interacted with dummy $\Gamma_{T}$. Specification (8) is estimated with the same method as before and using the data pooled from the control experiment and treatment $T$. Note that realized histories of shock $r_{t}^{n}$ and monetary policy inaction $\mathcal{I}_{t}$ are identical between the control and the treatment. Therefore, coefficients $\mathbf{c}_{\mathbf{r} 2}$ and $\mathbf{c}_{\mathbf{r} 3}$ identify treatment effects of communication on variable $E_{i t} X_{i t+1}$. To estimate treatment effects on $X_{i t}$ we use (8), replacing $\mathcal{I}_{t-1}$ with $\mathcal{I}_{t}$.

\footnotetext{
${ }^{14}$ Note that the absolute size of the surprise after an action is larger (smaller) than after an inaction if $\rho_{i}<0.5\left(\rho_{i}>0.5\right)$, and they are equal if $\rho_{i}=0.5$. Since $\rho_{i}=0.56$ in our experiments, this distinction is small and we are going to abstract from it in the rest of the paper, reporting only the results conditional on an expansionary monetary policy surprise.
} 


\subsection{Control experiment}

Participants are exposed to demand and monetary policy shocks throughout the experiment. To better gauge information problems facing participants, we compare responses in the control experiment with those in the FIRE model. Figure 1 shows responses to a +100 bps demand impulse and an expansionary monetary surprise. Under rational expectations, the demand shock stimulates both concurrent and future output and inflation, causing nominal interest rates to rise. The increase in nominal interest rates raises real interest rates, motivating a delay of the current spending till later periods. A rational agent will make unavoidable forecast errors on impact of the demand shock, but zero forecast errors thereafter. An expansionary monetary policy surprise results in higher expenditures and prices. Because the surprise occurs in the "evening" of the shock period, i.e., after forecasts have been submitted, these forecasts respond in the subsequent period and are zero thereafter since monetary surprises are not persistent.

Outcomes in the control experiment are determined by subjects' ability to (i) recognize the size and duration of fluctuations of relevant observables, (ii) discern the sources of those fluctuations, and (iii) incorporate changes in interest rates into their forecasts. The literature has emphasized that due to information constraints, forecasters only partially respond to shocks (Mankiw and Reis, 2010). That is the case in our experiment. Following the demand shock, individual price forecasts respond by a total of +104 bps after the first two periods ( +39 bps on impact and +65 bps in the subsequent period), and expenditure forecasts by +97 bps (Table 2 Panel A reports cumulative responses after two periods). Forecast responses dissipate to zero after four periods. Comparing with the FIRE model, forecasts are significantly more volatile, and they exhibit a hump-shaped pattern for prices and interest rates that is typical for expectations formed under substantial costs of acquiring, absorbing, and processing information (Reis, 2006).

Responses to an unexpected monetary policy surprise are smaller, but persist for at least twice as long. Different persistence of forecasts reflects different smoothness of forecast variables: individual prices and expenditures are at least twice as persistent after a 
monetary surprise than after a demand shock. As with demand shocks, aggregate forecasts are significantly more volatile than under rational expectations. The incomplete response of forecasts leads to a positive initial response of forecast errors, i.e., participants underanticipate changes in the target variables. For the demand shock, forecast error responses are similar in magnitude to the responses of forecasts themselves. As price and expenditure forecasts persist above forecast variables after the demand shock, forecast errors revert from positive to negative after two periods (Row 2 in Panel A of Figure 1). This highlights partial forecast adjustment not only at a point in time but also over time.

Forecast errors after monetary surprises are more volatile relative to forecasts, in part because monetary surprises are realized with a one-period delay. In contrast to demand shocks, forecast error responses are relatively short-lived, persisting for only one period after a monetary surprise (Row 2 in Panel B of Figure 1). This is because monetary surprises are not persistent and therefore their effects are easier to forecast. Notably, after monetary surprises, forecasts respond in the same direction as FIRE forecasts (Row 1, Panel B) indicating that subjects qualitatively understand the impact of interest rate changes on the variables they forecast.

Partial adjustment of forecast responses at the time of the shocks and over time implies in our LTF setting that individual and aggregate outcomes are both more volatile and more persistent relative to the full-information rational expectations case. In particular, the response of aggregate inflation to a monetary shock is hump-shaped, which is a feature that is hard to match in New Keynesian models without information rigidities where agents react immediately to the shock (Mankiw and Reis, 2002).

Two observations warrant additional explanation. First, individual expenditure forecast responses to a demand shock decrease in the FIRE model but increase in the experiment (Row 2, Panel A of Figure 1). Unlike rational agents, experiment participants anticipate an increase in household spending during the expansion, effectively behaving as myopic hand-to-mouth households. Such myopic behavior could be attributed to information costs (Reis, 2006) or to insufficient understanding of the stabilizing effects of monetary policy (Carvalho and Nechio, 2014). Another interpretation is that forecasters may over-react to 
realizations of past individual expenditures, a feature of "diagnostic" expectations discussed in Bordalo et al. (2018). Second, in the experiments we observe a positive output response to a demand shock that is short-lived and turning to negative right after the shock, whereas in the model it gradually subsides to zero (Row 3, Panel A of Figure 1). This is because in our calibrated framework, output is more sensitive to interest rate persistence than inflation. In the experiment, persistently high interest rates are needed to counteract lasting responses of inflation as prescribed by the Taylor rule, causing a contraction in output.

We also find substantial systematic differences across individual forecasters. To explore heterogeneity in forecasting behavior in the analysis, we split subjects into two groups by their forecasting ability. The "Top3" group includes subjects whose forecasting accuracy is ranked between 1 and 3 over the course of the entire experiment, and the "Bottom3" includes subjects ranked between 4 and 6 . We repeat estimations of the forecasting equations for each group separately. Not surprisingly, we find that forecasters with overall higher forecasting ability make much more accurate price and expenditure forecasts than the Bottom 3 group in response to a demand shock (Panel A Table 2). This difference in forecasting performance is not related to the ability to forecast interest rates as evidenced by similar forecasts errors for two groups (columns 10-11). Instead, it reflects more stable forecasts for Top3 forecasters, as shown on the left-side plots in Figure 2. Furthermore, the Bottom3 forecast responses to monetary surprises are much more widely dispersed, indicating substantial difficulties with gauging adequate response to a monetary surprise.

We also measure the "spread" in forecasts between two groups defined as the absolute difference between the mean Top3 forecast and the mean Bottom3 forecast. For interest rate forecast, the spread is akin to measures of forecast disagreement in the survey literature (Mankiw, Reis, and Wolfers, 2004). Mankiw and Reis (2010) demonstrate that a significant increase of forecast disagreement after a positive or negative shock is consistent with stickyinformation theories where information is updated infrequently at a fixed cost (Mankiw and Reis, 2002, 2006), whereas noisy-information theories (Woodford, 2001; Sims, 2003) predict no response. In the experiments, responses of the spread between interest rate forecasts are not statistically different from zero, and therefore we cannot reject the null of no response 
as in noisy-information theories. ${ }^{15}$

Having established the results in the control experiment, we go on to quantify the effects of communication on experimental outcomes in three COM treatments.

\section{Effects of Communication on Conditional Responses}

In this section we present the estimated treatment effects of central bank communication on individual and aggregate conditional responses.

\subsection{Individual forecasts}

Panel B in Tables 2-3 provides treatment effects expressed as the difference between the IRFs in treatment experiments and in the control experiment (cumulative responses in first two periods are provided). Figure 3 compares IRFs in treatment and control experiments.

Overall, central bank communication has a stabilizing influence on individual forecasts. In all COM treatments, forecast responses are more muted after a demand shock, and the associated forecast errors are smaller. Quantitatively, COM-BACK treatment has the largest effect, reducing price and expenditure forecasts by 33 and 73 bps after two periods, i.e., by about one-third and three-quarters, respectively, and interest rate forecasts by 16 bps or 40\%. The associated forecast errors decrease by a quarter for price and almost entirely for expenditures. The effects of FWD and COMMIT communication are smaller by about a half and are less significant. We find that stabilization of price and expenditure forecasts is not driven by subjects' ability to forecast interest rates, as treatment effects for interest rate forecasts are not very different across treatments.

What are the mechanisms that facilitate effective central bank communication? On the one hand, we document that treatment effects for interest rate forecasts and forecast errors

\footnotetext{
${ }^{15}$ The spreads between price forecasts and between expenditure forecasts are somewhat different from the "disagreement" measure in the literature. This is because, in the experiment, the forecasted variables are subject-specific and forecast spread may reflect different histories of individual variables. The spread between expenditure forecasts is not statistically different from zero after either shock, and neither is the spread between price forecasts for the demand shock. One exception is that price forecast spread decreases after a monetary surprise shock, implying that after a surprise forecasts, the Top 3 and Bototm 3 subjects tend to be closer to each other. See Sections L and M in Supplementary Material.
} 
are virtually zero, unlike significant effects for price and expenditure forecasts. This indicates that the effects of communication on individual price and expenditure forecasts operate via indirect channels, instead of directly via interest rate forecasts.

Our evidence suggests that such indirect channels work by making interest rate policy more salient and by providing an anchoring point for expectations. First, some of the reduction in forecast volatility is due to subjects paying more attention to interest rates. Table 3 (Panel B) shows that forecast responses for prices and expenditures are more sensitive to a monetary surprise, especially in COM-BACK treatment. The responsiveness of participants' attention supports the idea of state-dependence in the information updating process (Mackowiak and Wiederholt, 2012). Paciello and Wiederholt (2014) show that when agents' attention is responsive to economic conditions, monetary policy should pursue price-level stability. In the next section, we present evidence that effective central bank communication does improve aggregate price-level stability.

Second, it is more likely that subjects will incorporate information about future inflation and output gap into forecasts than they will interest rate information, as the latter requires more cognitive processing. Survey evidence (Jain and Sutherland, 2018) and experimental evidence (Mokhtarzadeh and Petersen, 2017) find that forecast dispersion decreases more consistently with inflation and output gap projections than with interest rate projections. Realized individual expenditures and prices tend to be smaller than subjective forecasts, thus providing a natural anchoring point. This is especially important for forecasters who are confused, unaware, or less informed about monetary policy, and who tend to put a significant weight on past experience in their forecasting decisions (Coibion et al., 2018).

Indeed, when we dissect responses by subjects' forecasting ability, we find that the communication effects in the experiments are almost entirely due to the effects on less informed subjects (Bottom3). Their price (expenditure) forecasts after a demand shock are reduced by one-half (completely) in COM-BACK treatment (see columns 3 and 6 in Table 2), and by almost one-half and by two-thirds in COM-FWD and COM-COMMIT treatments, respectively. Treatment effects for Top3 forecasters are not significantly different from zero in all experiments. These results suggest that communication is more effective when it is 
accessible to a wider public. Such communication is disbursed via simple and easy-to-process information and appeals to participants' recent experience, as in COM-BACK, rather than via more complex information, as presented in COM-FWD and COM-COMMIT.

This finding is consistent with Bholat et al. (2018), who report that visual summaries of the Bank of England's Inflation Report significantly improve comprehension over traditional executive summaries and help align the public's economic outlook with that of the Bank of England. Moreover, public comprehension and trust can be improved by relating the summary of economic outlook and monetary policy to people's everyday experiences. Literature on financial literacy has documented that accounting training programs or retirement seminars benefit mostly those at the low end of wealth or education. Drexler, Fischer, and Schoar (2014) show that teaching simple accounting heuristics rather than standard accounting procedures results in significantly greater revenues and fewer accounting errors, specifically among those with poor financial literacy skills.

The effectiveness of forward-looking communication, FWD and COMMIT, is determined to a large degree by participants' perception of the likelihood that the central bank will adhere to its policy pronouncements. We refer to this perception as "anchoring" of expectations. Imperfect anchoring may limit the impact of central bank policies, such as "lower for longer" interest rates at the zero lower bound, the unwinding of quantitative easing, or the pace of normalization of nominal interest rates. We denote COM-FWD participants as anchoring on the central bank's announcement if they move their interest rate forecast in the same direction as the central bank's projected rate change. We denote a COM-COMMIT participant as anchoring on the central bank's commitment if she forecasts the observed interest rate to stay unchanged during periods of inaction. ${ }^{16}$ Even in COM-BACK treatment, participants may anchor on announcements of past interest rate changes despite their irrelevance in the determination of future interest rates. Anchoring can either manifest itself as the participant forecasting the previous period's interest rate level or forecasting in the direction of the previous interest rate change.

\footnotetext{
${ }^{16}$ Because of the possibility of participants rounding their forecasts in COM-FWD, we denote anchoring as a forecast within $10 \mathrm{bps}$ from the central bank's intended rate.
} 
We conduct a series of random effects probit regressions to evaluate the potential drivers of anchoring during periods of communication, see Section J in Supplementary Material. Experience has distinctly different effects across treatments. Anchoring declines over time in COM-FWD, but it improves with experience in COM-BACK and COM-COMMIT. Longer periods of recent monetary policy inaction significantly reduce participants' willingness to anchor on the central bank's communication in COM-FWD and COM-COMMIT (there are no announcements during inaction in COM-BACK treatment). Expectations of the Bottom3 group are anchored as much as for the Top3 participants in COM-BACK treatment, and they are more anchored in COM-COMMIT treatment. By contrast, Bottom3 forecasts are less anchored in COM-FWD treatment. Hence, we see evidence of central bank communication providing focal points for participants' expectations, explicitly referencing the past (BACK) or future (COMMIT) interest rates. By contrast, qualitative guidance (FWD) is less effective for managing the expectations of the Bottom3, who would benefit most from communication, likely because it provides no explicit focal points.

\subsection{Aggregate outcomes}

Panel B in Table 4 provides treatment effects for inflation, output gap and interest rate responses, and Figure 4 compares aggregate IRFs in treatment and control experiments. The table provides cumulative responses after two and ten periods after the shock to give a sense of how much treatment effects differ with the response horizon.

In all communication treatments, aggregate responses to demand shocks are more stable. Treatment effects increase with the response horizon, indicating that benefits of communication accrue over time. Quantitatively, the largest stabilization occurs in COM-BACK treatment, where the cumulative inflation response ten periods after the demand shock is two times smaller than in the control experiment. COM-COMMIT delivers a similar reduction in inflation, but it also comes with a decrease in output, whereas output rebounds in COM-BACK treatment. Communication effects are the smallest and statistically insignificant in COM-FWD treatment. Treatment effects on inflation and output are insignificant 
for monetary surprises. By contrast, interest rate responses are two times smaller in COMBACK and COM-COMMIT than in the control experiment, and statistically insignificant. This indicates that interest rate changes are more influential when they are accompanied by these types of communication.

What is especially striking is that in COM-BACK and to a lesser extent in COMCOMMIT treatments the response of inflation for either shock overshoots the target along the adjustment path (top row, Panels A and B, Figure 4). In these treatments, communication stabilizes individual expenditure forecasts by more than it stabilizes price forecasts. More stable forecasts imply more stable outcomes: for example, positive individual expenditure responses to a demand shock in the control experiment are reduced to zero after just two periods in COM-BACK treatment, whereas individual price responses are reduced by less than one-third. On aggregate, output response turns negative shortly after the shock, putting an additional downward pressure on the response of the price level. Hence, BACK and COMMIT communication achieve better aggregate price-level stability relative to no communication by effectively stabilizing individual spending behavior. Previous work emphasized how the pursuit of price-level targeting may yield stabilization benefits relative to inflation targeting because of additional stabilization of inflation expectations (Vestin, 2006). Ball, Mankiw, and Reis (2005) show that in models with sticky-information frictions, price-level targeting is optimal. Our results suggest that when information frictions abound, substantial additional price-level stability can be achieved by effective communication, over and above stabilization from interest rate policy.

The treatment effects on output and inflation are smaller than they would have been had interest rates not adjusted countercyclically, as prescribed by the Taylor rule. Indeed, in all experiments, interest rate increase is smaller after the demand shock in line with smaller output and inflation responses. For example, the COM-BACK treatment effect on interest rate response after ten periods is $-118 \mathrm{bps}$, or two-thirds of the $+172 \mathrm{bps}$ response (column 3 in Table 4). To assess the magnitude of communication effects on output and inflation, we estimate their counterfactual impulse responses by setting treatment effect on interest rate to be zero. Effectively, we compensate the responses of the interest rate in COM treatments 
so that they exactly match the responses in the control experiment. The resulting additional responses in inflation and output depend on their respective elasticities with respect to exogenous interest rate variations. We approximate these elasticities using inflation and output responses in the control experiment. Section G in Supplementary Material explains how we account for countercyclical responses of monetary policy.

Table 4 shows that treatment effects are substantially larger when we account for countercyclical adjustment of interest rates. For example, in COM-BACK the communication effect on the inflation response after 10 periods of a demand shock is -91 bps, almost double the estimated treatment effect and close to fully offsetting +96 bps response in the control experiment. In COM-COMMIT treatment the effect is somewhat smaller. Both inflation and output are lower by 72 bps, with the effect being statistically significant for inflation. One distinct trait of COMMIT communication is that it is most effective in increasing the impact of interest rate changes on the economy. The counterfactual treatment effect on output's 10-period response is +50 bps (versus +64 bps in the control), the largest in all experiments.

\section{$5 \quad$ Discussion and Conclusions}

The overarching result in our experiments is that simpler, more accessible central bank communication tends to be more effective in influencing participants' forecasts. In our experiment, the best stabilization is achieved by central bank communication that relates to participants' recent experience. Stabilization benefits materialize even though the central bank's messages lack content about the future course of the economy. Indeed, improvements in forecasting performance across communication treatments are not accompanied by proportional improvements in interest rate forecasts. Rather, simplified and relatable announcements have especially strong impact on less-informed decision-makers.

The effects of communication do not so much operate via their direct influence on forecasters' ability to predict future nominal interest rates; rather, they work via indirect mechanisms that promote public understanding of central banks' goals and actions in the current 
economic context. Coibion, Gorodnichenko, and Kumar (2018) argue that central banks can "pierce this veil of inattention" by focusing their communication on helping less-informed firms or households distill recent economic conditions and understand central banks' actions. The upshot in our paper is that the increase in accessibility of central bank information to the general public is a promising direction for improving the effectiveness of central bank communication. Future research should explicitly incorporate behavioral aspects into macroeconomic models and analysis of monetary policy (Ball, Mankiw, and Reis, 2005) and expand the use of empirical methods - such as field and lab experiments, and online surveys - to augment our understanding of the channels that render central banks' communication effective (Haldane and McMahon, 2018).

Our findings support a cautious narrative for implications of forward-looking types of communication. We do not find any support for explicit communication of the path of nominal interest rates. Neither qualitative nor quantitative forward guidance yields substantial improvement in interest rate forecasts, which could be associated with the lack of clarity of the messaging or the lack of anchoring on the central bank's pronouncements. The lack of clarity in existing qualitative communications has been emphasized by Kahn (2007), who concludes that there is little to be gained from announcing an explicit numerical policy path.

In the experiments, participants' economic forecasts show some improvements only when forward guidance is quantitative and time-contingent, but announcements are less useful when they are qualitative and state-contingent. The importance of credibility for the effectiveness of central bank communication has been highlighted in the context of unconventional monetary policies (Charbonneau and Rennison, 2015) and "open mouth" operations (Guthrie and Wright, 2000). Arifovic and Petersen (2017) find that communication of history-dependent quantitative inflation targets at the ZLB can lead to greater loss of credibility and more instability if the central bank is unsuccessful at coordinating expectations in its intended direction. With low financial and especially macroeconomic literacy, a central bank may be easily misunderstood by the public (Haldane and McMahon, 2018). When communication is associated with a noise that is common among the public, it may draw private beliefs away from fundamentals (Amato, Morris, and Shin, 2002). Communication 
can also amplify private noise and lead to confusion when there are differences in interpretation of the same message across individuals (Coenen et al., 2017). Empirical evidence on time-contingent forward guidance is also mixed. Filardo and Hofmann (2014) provide evidence that calendar-based forward guidance in the United States has been effective, although the effectiveness declined over time. Ehrmann et al. (2019) provide cross-country evidence that time-contingent forward guidance can increase interest rate responsiveness to macroeconomic news. Future work should seek more empirical evidence on the effects of forward guidance and continue investigating the mechanisms that may limit its effectiveness.

We show that central bank communication can deliver stabilization benefits over and above those achieved via interest rate policy. In the experiments, communication has greater influence on spending decisions than on price decisions, which leads to a more transient response of the output gap to shocks relative to inflation response. As a result, inflation overshoots the target in communication treatments, which is similar to a response under history-dependent monetary policies, such as price-level targeting, nominal GDP targeting, or average inflation targeting. Our findings therefore emphasize an emergent property of communication as an independent stabilization monetary policy tool (Coibion et al., 2018). Further empirical evidence on price stabilization benefits of central bank communication is certainly warranted.

Our methodology includes novel elements that lead to evidence linking information rigidities to the effects of central bank communication, such as monetary policy inaction, the use of interest rate forecasts, heterogeneity of individual forecast decisions, and variation in the type of central bank announcements. Further evidence on the nature and degree of information rigidities and expectations formation can advance our understanding of effective communication strategies. For example, future experimental work can supplement our design with information on forecast revisions currently explored in survey data (Coibion and Gorodnichenko, 2015; Bordalo et al., 2018).

We also abstracted from the question of how the central bank's messaging can be delivered to a wider audience, since experiment participants had immediate and continuous access to all relevant information. Household and firm survey data show that the general public is 
ignorant about central bank objectives and insensitive to their communications (Coibion et al., 2018; D'Acunto et al., 2019). Coibion, Gorodnichenko, and Kumar (2018) provide evidence from a survey of New Zealand firms that the main source of inaccurate inflation expectations by uninformed firms is their inattention to recent economic conditions. How much people are willing to act on their expectations remains very much an open question that individual choice, market, and production economy experiments can shed light on (Davis and Korenok, 2011;Armantier et al., 2015; Petersen, 2015). Quasi-experiments and online experiments focusing on decisions of a large number of non-financial and non-professional forecasters will surely yield fruitful evidence on behavioral aspects of information rigidities and on better means of getting central banks' messages across (Coibion, Gorodnichenko, and Weber, 2019; Arifovic et al., 2018; Hommes, Kopányi-Peuker, and Sonnemans, 2019).

\section{References}

Adam, Klaus. 2007. "Experimental evidence on the persistence of output and inflation." The Economic Journal 117 (520):603-636.

Amato, Jeffery D., Stephen Morris, and Hyun Song Shin. 2002. "Communication and Monetary Policy." Oxford Review of Economic Policy 18 (4):495-503.

Arifovic, Jasmina, Cars Hommes, Anita Kopányi-Peuker, and Isabelle Salle. 2018. "Are sunspots effective in a big crowd? Evidence from a large-scale bank run experiment." Tech. rep., Working paper.

Arifovic, Jasmina and Luba Petersen. 2017. "Stabilizing expectations at the zero lower bound: Experimental evidence." Journal of Economic Dynamics and Control 82:21-43.

Armantier, Olivier, Wändi Bruine de Bruin, Giorgio Topa, Wilbert Van Der Klaauw, and Basit Zafar. 2015. "Inflation expectations and behavior: Do survey respondents act on their beliefs?" International Economic Review 56 (2):505-536.

Assenza, Tiziana, Peter Heemeijer, Cars Hommes, and Domenico Massaro. 2013. "Individual Expectations and Aggregate Macro Behavior." Tinbergen Institute Discussion Papers 13016/II, Tinbergen Institute.

Ball, Laurence, Gregory N. Mankiw, and Ricardo Reis. 2005. "Monetary policy for inattentive economies." Journal of Monetary Economics 52 (4):703-725.

Bao, Te, John Duffy, and Cars Hommes. 2013. "Learning, forecasting and optimizing: An experimental study." European Economic Review 61:186-204. 
Bholat, David, Nida Broughton, Alice Parker, Janna Ter Meer, and Eryk Walczak. 2018. "Enhancing central bank communications with behavioural insights." Bank of England working papers 750, Bank of England.

Bholat, David, Stephen Hans, Pedro Santos, and Cheryl Schonhardt-Bailey. 2015. Text mining for central banks. No. 33 in Handbooks. Centre for Central Banking Studies, Bank of England.

Blinder, Alan S., Michael Ehrmann, Marcel Fratzscher, Jakob De Haan, and David-Jan Jansen. 2008. "Central Bank Communication and Monetary Policy: A Survey of Theory and Evidence." Journal of Economic Literature 46 (4):910-945.

Bordalo, Pedro, Nicola Gennaioli, Yueran Ma, and Andrei Shleifer. 2018. "Over-reaction in Macroeconomic Expectations." NBER Working Papers 24932, National Bureau of Economic Research, Inc.

Campbell, Jeffrey R., Jonas D. M. Fisher, Alejandro Justiniano, and Leonardo Melosi. 2017. "Forward Guidance and Macroeconomic Outcomes since the Financial Crisis." NBER Macroeconomics Annual 31 (1):283-357.

Capistrán, Carlos and Allan Timmermann. 2009. "Disagreement and Biases in Inflation Expectations." Journal of Money, Credit and Banking 41 (2-3):365-396.

Carvalho, Carlos and Fernanda Nechio. 2014. "Do people understand monetary policy?" Journal of Monetary Economics 66 (C):108-123.

Charbonneau, Karyne B. and Lori Rennison. 2015. "Forward Guidance at the Effective Lower Bound: International Experience." Discussion Papers 15-15, Bank of Canada.

Clarida, Richard, Jordi Galí, and Mark Gertler. 1999. "The Science of Monetary Policy: A New Keynesian Perspective." Journal of Economic Literature 37 (4):1661-1707.

Coenen, Günter, Michael Ehrmann, Gaetano Gaballo, Peter Hoffmann, Anton Nakov, Stefano Nardelli, Eric Persson, and Georg Strasser. 2017. "Communication of monetary policy in unconventional times." CFS Working Paper Series 578, Center for Financial Studies (CFS).

Coibion, Olivier and Yuriy Gorodnichenko. 2012. "What Can Survey Forecasts Tell Us about Information Rigidities?" Journal of Political Economy 120 (1):116-159.

_ 2015. "Information Rigidity and the Expectations Formation Process: A Simple Framework and New Facts." American Economic Review 105 (8):2644-78.

Coibion, Olivier, Yuriy Gorodnichenko, and Saten Kumar. 2018. "How do firms form their expectations? New survey evidence." American Economic Review 108 (9):2671-2713.

Coibion, Olivier, Yuriy Gorodnichenko, Saten Kumar, and Mathieu Pedemonte. 2018. "Inflation Expectations as a Policy Tool?" NBER Working Papers 24788, National Bureau of Economic Research, Inc. 
Coibion, Olivier, Yuriy Gorodnichenko, and Michael Weber. 2019. "Monetary Policy Communications and their Effects on Household Inflation Expectations." NBER Working Papers 25482, National Bureau of Economic Research, Inc.

Cornand, Camille and Paul Hubert. 2018. "On the external validity of experimental inflation forecasts: A comparison with five categories of field expectations." Working Papers 1821, Groupe d'Analyse et de Théorie Economique Lyon St-Étienne (GATE Lyon St-Étienne), Université de Lyon.

Cornand, Camille and Cheick Kader M'baye. 2018. "Does inflation targeting matter? An experimental investigation." Macroeconomic Dynamics 22 (2):362-401.

Croushore, Dean D. 1997. "The Livingston survey: Still useful after all these years." Business Review-Federal Reserve Bank of Philadelphia 2:1-12.

D’Acunto, Francesco, Daniel Hoang, Maritta Paloviita, and Michael Weber. 2019. "Human frictions in the transmission of economic policy." Working Paper Series in Economics 128, Karlsruhe Institute of Technology (KIT), Department of Economics and Business Engineering.

Davis, Douglas and Oleg Korenok. 2011. "Nominal shocks in monopolistically competitive markets: An experiment." Journal of Monetary Economics 58 (6-8):578-589.

Drexler, Alejandro, Greg Fischer, and Antoinette Schoar. 2014. "Keeping it simple: Financial literacy and rules of thumb." American Economic Journal: Applied Economics 6 (2):1-31.

Ehrmann, Michael, Gaetano Gaballo, Peter Hoffmann, and Georg Strasser. 2019. "Can more public information raise uncertainty? The international evidence on Forward Guidance." manuscript.

Filardo, Andrew J. and Boris Hofmann. 2014. "Forward guidance at the zero lower bound." Bis quarterly review, Bank for International Settlements.

Guthrie, Graeme and Julian Wright. 2000. "Open mouth operations." Journal of Monetary Economics 46 (2):489-516.

Haldane, Andrew and Michael McMahon. 2018. "Central bank communications and the general public." In AEA Papers and Proceedings, vol. 108. 578-83.

Hommes, Cars, Anita Kopányi-Peuker, and Joep Sonnemans. 2019. "Bubbles, crashes and information contagion in large-group asset market experiments." Tinbergen Institute Discussion Papers 19-016/II, Tinbergen Institute.

Hommes, Cars, Domenico Massaro, and Isabelle Salle. 2019. "Monetary and Fiscal Policy Design at the Zero Lower Bound: Evidence from the Lab." Economic Inquiry 57 (2):11201140 .

Hommes, Cars, Joep Sonnemans, Jan Tuinstra, and Henk Van de Velden. 2008. "Expectations and bubbles in asset pricing experiments." Journal of Economic Behavior $\&$ Organization 67 (1):116-133. 
Jain, Monica and Christopher S. Sutherland. 2018. "How Do Central Bank Projections and Forward Guidance Influence Private-Sector Forecasts?" Staff Working Papers 18-2, Bank of Canada.

Kahn, George A. 2007. "Communicating a policy path: the next frontier in central bank transparency?" Economic Review (Q I):25-51.

Lamla, Michael J. and Dmitri V. Vinogradov. 2019. "Central Bank Announcements: Big News for Little People?" manuscript.

Mackowiak, Bartosz and Mirko Wiederholt. 2012. "Information Processing and Limited Liability." American Economic Review 102 (3):30-34.

Mankiw, Gregory N. and Ricardo Reis. 2002. "Sticky Information Versus Sticky Prices: A Proposal to Replace the New Keynesian Phillips Curve." Quarterly Journal of Economics 117 (4):1295-1328.

_. 2006. "Pervasive Stickiness." American Economic Review 96 (2):164-169.

Mankiw, N. Gregory and Ricardo Reis. 2010. "Imperfect Information and Aggregate Supply." In Handbook of Monetary Economics, Handbook of Monetary Economics, vol. 3, edited by Benjamin M. Friedman and Michael Woodford, chap. 5. Elsevier, 183-229.

Mankiw, N. Gregory, Ricardo Reis, and Justin Wolfers. 2004. "Disagreement about Inflation Expectations." In NBER Macroeconomics Annual 2003, Volume 18, NBER Chapters. National Bureau of Economic Research, Inc, 209-270.

Marimon, Ramon and Shyam Sunder. 1994. "Expectations and learning under alternative monetary regimes: an experimental approach." Economic Theory 4 (1):131-162.

Mauersberger, Felix. 2017. "Monetary Policy Rules in a Non-Rational World: A Macroeconomic Experiment." Discussion Paper Series 1617 01, Columbia University, Department of Economics.

Mirdamadi, Michael and Luba Petersen. 2018. "Macroeconomic Literacy and Expectations." Working paper, Simon Fraser University, Department of Economics.

Moessner, Richhild, David-Jan Jansen, and Jakob de Haan. 2017. "Communication About Future Policy Rates in Theory and Practice: A Survey." Journal of Economic Surveys 31 (3):678-711.

Mokhtarzadeh, Fatemeh and Luba Petersen. 2017. "Coordinating expectations through central bank projections." Working paper, Simon Fraser University, Department of Economics.

Nagel, Rosemarie. 1995. "Unraveling in guessing games: An experimental study." The American Economic Review 85 (5):1313-1326.

Noussair, Charles N, Damjan Pfajfar, and Janos Zsiros. 2015. "Pricing decisions in an experimental dynamic stochastic general equilibrium economy." Journal of Economic Behavior \& Organization 109:188-202.

Ottaviani, Marco and Peter Norman Sørensen. 2006. "The strategy of professional forecasting." Journal of Financial Economics 81 (2):441-466. 
Paciello, Luigi and Mirko Wiederholt. 2014. "Exogenous Information, Endogenous Information, and Optimal Monetary Policy." Review of Economic Studies 81 (1):356-388.

Pesaran, M. Hashem and Martin Weale. 2006. Survey Expectations, Handbook of Economic Forecasting, vol. 1, chap. 14. Elsevier, 715-776.

Petersen, Luba. 2015. "Do expectations and decisions respond to monetary policy?" Journal of Economic Studies 42 (6):972-1004.

Pfajfar, Damjan and Blaž Žakelj. 2016. "Inflation expectations and monetary policy design: Evidence from the laboratory." Macroeconomic Dynamics :1-41.

Preston, Bruce. 2005. "Learning about Monetary Policy Rules when Long-Horizon Expectations Matter." International Journal of Central Banking 1 (2):81-126.

Reis, Ricardo. 2006. "Inattentive consumers." Journal of Monetary Economics 53 (8):17611800.

Sims, Christopher A. 2003. "Implications of rational inattention." Journal of Monetary Economics 50 (3):665-690.

Vestin, David. 2006. "Price-level versus inflation targeting." Journal of Monetary Economics $53(7): 1361-1376$.

Woodford, Michael. 2001. "Imperfect Common Knowledge and the Effects of Monetary Policy." NBER Working Papers 8673, National Bureau of Economic Research, Inc.

- 2013. "Macroeconomic Analysis Without the Rational Expectations Hypothesis." Annual Review of Economics 5 (1):303-346. 
Table 1: Summary of second moments

\begin{tabular}{|c|c|c|c|c|c|}
\hline & \multirow{2}{*}{$\begin{array}{l}\text { FIRE } \\
\text { model }\end{array}$} & \multirow{2}{*}{$\begin{array}{c}\text { Control } \\
\text { experiment }\end{array}$} & \multicolumn{3}{|c|}{ Treatment experiments } \\
\hline & & & COM-BACK & COM-FWD & COM-COMMIT \\
\hline & $(1)$ & $(2)$ & (3) & (4) & $(5)$ \\
\hline \multicolumn{6}{|c|}{ Panel A: Volatilities of subject-level variables } \\
\hline \multicolumn{6}{|l|}{ Price } \\
\hline std(forecast) / std(price) & 0.210 & 1.004 & 0.964 & 1.005 & 1.022 \\
\hline std(f.e.) / std(price) & 1.209 & 1.001 & 1.054 & 1.039 & 1.741 \\
\hline std(price) / std(agg price) & 1.000 & 1.105 & 1.093 & 1.125 & 1.114 \\
\hline \multicolumn{6}{|l|}{ Expenditures } \\
\hline std(forecast) / std(exp-s) & 0.622 & 0.803 & 0.854 & 0.824 & 0.885 \\
\hline std(f.e.) / std(exp-s) & 0.783 & 0.845 & 0.741 & 0.747 & 1.009 \\
\hline std(exp-s) / std(agg exp-s) & 1.000 & 3.735 & 2.539 & 4.323 & 2.544 \\
\hline \multicolumn{6}{|l|}{ Interest rate } \\
\hline std(forecast) / std(int rate) & 0.493 & 0.970 & 0.877 & 0.898 & 0.979 \\
\hline std(f.e.) / std(int rate) & 0.870 & 1.244 & 1.293 & 1.320 & 1.310 \\
\hline Number of observations & & 2983 & 2903 & 2943 & 2974 \\
\hline \multicolumn{6}{|c|}{ Panel B: Volatilities and variance decompositions of aggregate variables } \\
\hline Inflation, std (bps) & 33 & 196 & 186 & 169 & 211 \\
\hline demand shocks & 0.950 & 0.890 & 0.821 & 0.950 & 0.865 \\
\hline monetary policy surprises & 0.050 & 0.110 & 0.179 & 0.050 & 0.135 \\
\hline Output, std (bps) & 72 & 223 & 258 & 213 & 278 \\
\hline demand shocks & 0.924 & 0.866 & 0.854 & 0.850 & 0.822 \\
\hline monetary policy surprises & 0.076 & 0.134 & 0.146 & 0.150 & 0.178 \\
\hline Interest rate, std (bps) & 37 & 274 & 255 & 239 & 287 \\
\hline demand shocks & 0.701 & 0.664 & 0.556 & 0.694 & 0.686 \\
\hline monetary policy surprises & 0.299 & 0.336 & 0.444 & 0.306 & 0.314 \\
\hline Number of observations & & 498 & 487 & 490 & 490 \\
\hline
\end{tabular}

Notes. Panel A provides standard deviations of forecasts and forecast errors for individual price $\left(p_{j t}^{*}\right)$, individual expenditures $\left(\bar{v}_{i t}\right)$, and interest rate $\left(i_{t}\right)$, expressed relative to standard deviations in their respective levels or relative to aggregate price $\left(\sum_{j} p_{j t}^{*}\right)$, aggregate expenditures $\left(\sum_{i} \bar{v}_{i t}\right)$, or interest rate. Panel $\mathrm{B}$ provides standard deviations for inflation, output and interest rate, and the fractions of their variance explained by demand shocks and monetary policy surprises. Columns: (1) Model under full-information rational expectations, (2) Control experiment, (3)-(5) Treatment experiments, COM-BACK, COM-FWD, and COM-COMMIT. 
Table 2: Individual responses to a +100 bps demand impulse

\begin{tabular}{|c|c|c|c|c|c|c|c|c|c|}
\hline \multirow{3}{*}{ Experiment } & \multicolumn{3}{|c|}{ Individual price } & \multicolumn{3}{|c|}{ Individual expenditures } & \multicolumn{3}{|c|}{ Interest rate } \\
\hline & All & Top3 & Bottom3 & All & Top3 & Bottom3 & All & Top3 & Bottom3 \\
\hline & $(1)$ & $(2)$ & (3) & $(4)$ & $(5)$ & $(6)$ & $(7)$ & $(8)$ & (9) \\
\hline \multicolumn{10}{|c|}{ Panel A: Control experiment } \\
\hline Forecast & $\begin{array}{c}104^{* * *} \\
(9)\end{array}$ & $\begin{array}{c}80^{* * *} \\
(8)\end{array}$ & $\begin{array}{c}130^{* * *} \\
(14)\end{array}$ & $\begin{array}{l}97^{* * *} \\
(15)\end{array}$ & $\begin{array}{l}54^{* * *} \\
(10)\end{array}$ & $\begin{array}{c}144^{* * *} \\
(27)\end{array}$ & $\begin{array}{c}42^{* * *} \\
(5)\end{array}$ & $\begin{array}{c}38^{* * *} \\
(6)\end{array}$ & $\begin{array}{c}47^{* * *} \\
(7)\end{array}$ \\
\hline Forecast errors & $\begin{array}{c}108^{* * *} \\
(9)\end{array}$ & $\begin{array}{c}100^{* * *} \\
(9)\end{array}$ & $\begin{array}{c}113^{* * *} \\
(15)\end{array}$ & $\begin{array}{l}52^{* * *} \\
(18)\end{array}$ & $\begin{array}{l}17 \\
(12)\end{array}$ & $\begin{array}{l}90^{* *} \\
(37)\end{array}$ & $\begin{array}{l}57^{* * *} \\
(13)\end{array}$ & $\begin{array}{l}56^{* * *} \\
(13)\end{array}$ & $\begin{array}{l}59^{* * *} \\
(13)\end{array}$ \\
\hline \multicolumn{10}{|c|}{ Panel B: Treatment effects (Treatment minus Control) } \\
\hline \multicolumn{10}{|l|}{ COM-BACK } \\
\hline Forecast & $\begin{array}{c}-33^{* *} \\
(15)\end{array}$ & $\begin{array}{l}-3 \\
(14)\end{array}$ & $\begin{array}{c}-64^{* * *} \\
(25)\end{array}$ & $\begin{array}{c}-73^{* * *} \\
(24)\end{array}$ & $\begin{array}{l}-8 \\
(17)\end{array}$ & $\begin{array}{c}-141^{* * *} \\
(45)\end{array}$ & $\begin{array}{c}-16^{* *} \\
(7)\end{array}$ & $\begin{array}{l}-9 \\
(9)\end{array}$ & $\begin{array}{c}-25^{\star *} \\
(11)\end{array}$ \\
\hline Forecast errors & $\begin{array}{r}-25^{\star} \\
(15)\end{array}$ & $\begin{array}{l}-18 \\
(16)\end{array}$ & $\begin{array}{l}-26 \\
(24)\end{array}$ & $\begin{array}{c}-52^{*} \\
(30)\end{array}$ & $\begin{array}{c}8 \\
(20)\end{array}$ & $\begin{array}{r}-102^{*} \\
(58)\end{array}$ & $\begin{array}{l}-11 \\
(18)\end{array}$ & $\begin{array}{l}-14 \\
(18)\end{array}$ & $\begin{array}{l}-9 \\
(20)\end{array}$ \\
\hline \multicolumn{10}{|l|}{ COM-FWD } \\
\hline Forecast & $\begin{array}{l}-18 \\
(12)\end{array}$ & $\begin{array}{c}8 \\
(12)\end{array}$ & $\begin{array}{c}-49 * * * \\
(19)\end{array}$ & $\begin{array}{c}-39^{*} \\
(20)\end{array}$ & $\begin{array}{l}13 \\
(15)\end{array}$ & $\begin{array}{c}-95^{* * *} \\
(36)\end{array}$ & $\begin{array}{c}-16^{* *} \\
(7)\end{array}$ & $\begin{array}{c}-13 \\
(8)\end{array}$ & $\begin{array}{c}-18 \\
(10)\end{array}$ \\
\hline Forecast errors & $\begin{array}{l}-10 \\
(12)\end{array}$ & $\begin{array}{l}-4 \\
(13)\end{array}$ & $\begin{array}{l}-13 \\
(19)\end{array}$ & $\begin{array}{l}-44^{*} \\
(26)\end{array}$ & $\begin{array}{c}6 \\
(17)\end{array}$ & $\begin{array}{l}-92^{*} \\
(49)\end{array}$ & $\begin{array}{l}19 \\
(17)\end{array}$ & $\begin{array}{l}21 \\
(16)\end{array}$ & $\begin{array}{l}17 \\
(18)\end{array}$ \\
\hline \multicolumn{10}{|l|}{ СОМ-СОМMIT } \\
\hline Forecast & $\begin{array}{l}-16 \\
(13)\end{array}$ & $\begin{array}{c}8 \\
(14)\end{array}$ & $\begin{array}{c}-44^{*} \\
(21)\end{array}$ & $\begin{array}{c}-34^{*} \\
(20)\end{array}$ & $\begin{array}{c}7 \\
(18)\end{array}$ & $\begin{array}{c}-101^{* * *} \\
(33)\end{array}$ & $\begin{array}{l}-5 \\
(8)\end{array}$ & $\begin{array}{c}4 \\
(11)\end{array}$ & $\begin{array}{l}-13 \\
(10)\end{array}$ \\
\hline Forecast errors & $\begin{array}{l}-4 \\
(13)\end{array}$ & $\begin{array}{c}0 \\
(15)\end{array}$ & $\begin{array}{l}-5 \\
(21)\end{array}$ & $\begin{array}{l}-22 \\
(26)\end{array}$ & $\begin{array}{c}8 \\
(22)\end{array}$ & $\begin{array}{c}-82^{*} \\
(45)\end{array}$ & $\begin{array}{c}-13 \\
(18)\end{array}$ & $\begin{array}{l}-16 \\
(19)\end{array}$ & $\begin{array}{l}-12 \\
(20)\end{array}$ \\
\hline
\end{tabular}

Notes. Panel A provides cumulative impulse responses (CIRFs) to a +100 bps demand impulse for the first two periods. CIRFs are constructed from the estimated equations (6)-(7). Standard errors (in parentheses) and confidence intervals are based on 1000 bootstrap simulations; ${ }^{* * *},{ }^{* *}$, and ${ }^{*}$ denote significant values at $1 \%, 5 \%$, and $10 \%$ confidence levels. Columns (1)-(3) provide CIRFs for forecasts and forecast errors for individual price, $p_{j t}^{*}$, estimated for all subjects (column 1), Top3 subjects (column 2), and Bottom3 subjects (column 3). Columns (4)-(6) provide the results for individual expenditures, $\bar{v}_{i t}$, and columns (7)-(9) provide the results for the interest rate. Panel B provides treatment effects, the differences between CIRFs for Treatment experiments (constructed from the estimated equation 8) and CIRFs for the Control experiment. 
Table 3: Individual responses to an expansionary monetary surprise

\begin{tabular}{|c|c|c|c|c|c|c|c|c|c|}
\hline \multirow{3}{*}{ Experiment } & \multicolumn{3}{|c|}{ Individual price } & \multicolumn{3}{|c|}{ Individual expenditures } & \multicolumn{3}{|c|}{ Interest rate } \\
\hline & All & Top3 & Bottom3 & All & Top3 & Bottom3 & All & Top3 & Bottom3 \\
\hline & $(1)$ & $(2)$ & (3) & $(4)$ & $(5)$ & (6) & $(7)$ & (8) & (9) \\
\hline \multicolumn{10}{|c|}{ Panel A: Control experiment } \\
\hline Forecast & $\begin{array}{l}8 \\
(5)\end{array}$ & $\begin{array}{c}10^{* *} \\
(4)\end{array}$ & $\begin{array}{l}5 \\
(8)\end{array}$ & $\begin{array}{c}28^{* * *} \\
(7)\end{array}$ & $\begin{array}{c}24^{* * *} \\
(5)\end{array}$ & $\begin{array}{l}33^{* *} \\
(14)\end{array}$ & $\begin{array}{c}-22^{* * *} \\
(3)\end{array}$ & $\begin{array}{c}-16^{* * *} \\
(4)\end{array}$ & $\begin{array}{c}-28^{* * *} \\
(5)\end{array}$ \\
\hline Forecast errors & $\begin{array}{c}21^{* *} \\
(8)\end{array}$ & $\begin{array}{c}31^{* * *} \\
(9)\end{array}$ & $\begin{array}{l}12 \\
\text { (13) }\end{array}$ & $\begin{array}{l}66^{* * *} \\
(18)\end{array}$ & $\begin{array}{l}90^{* * *} \\
(11)\end{array}$ & $\begin{array}{l}50 \\
(33)\end{array}$ & $\begin{array}{c}-66^{* * *} \\
(12)\end{array}$ & $\begin{array}{c}-67^{* * *} \\
(12)\end{array}$ & $\begin{array}{c}-67^{* * *} \\
(12)\end{array}$ \\
\hline \multicolumn{10}{|c|}{ Panel B: Treatment effects (Treatment minus Control) } \\
\hline \multicolumn{10}{|l|}{ COM-BACK } \\
\hline Forecast & $\begin{array}{c}18^{*} \\
(8)\end{array}$ & $\begin{array}{l}3 \\
(8)\end{array}$ & $\begin{array}{l}27^{* *} \\
(14)\end{array}$ & $\begin{array}{l}27^{* *} \\
(12)\end{array}$ & $\begin{array}{l}9 \\
(8)\end{array}$ & $\begin{array}{l}42^{*} \\
(23)\end{array}$ & $\begin{array}{l}3 \\
(5)\end{array}$ & $\begin{array}{l}-3 \\
(6)\end{array}$ & $\begin{array}{l}9 \\
(7)\end{array}$ \\
\hline Forecast errors & $\begin{array}{l}27^{* *} \\
(13)\end{array}$ & $\begin{array}{l}25^{*} \\
(14)\end{array}$ & $\begin{array}{l}36 \\
(22)\end{array}$ & $\begin{array}{l}17 \\
(28)\end{array}$ & $\begin{array}{l}-4 \\
(19)\end{array}$ & $\begin{array}{l}38 \\
(50)\end{array}$ & $\begin{array}{l}14 \\
(17)\end{array}$ & $\begin{array}{l}16 \\
(17)\end{array}$ & $\begin{array}{l}16 \\
(18)\end{array}$ \\
\hline \multicolumn{10}{|l|}{ COM-FWD } \\
\hline Forecast & $\begin{array}{l}1 \\
(6)\end{array}$ & $\begin{array}{l}2 \\
(7)\end{array}$ & $\begin{array}{c}0 \\
(10)\end{array}$ & $\begin{array}{l}-7 \\
(10)\end{array}$ & $\begin{array}{l}3 \\
(7)\end{array}$ & $\begin{array}{l}-13 \\
(18)\end{array}$ & $\begin{array}{l}-3 \\
(4)\end{array}$ & $\begin{array}{l}-6 \\
(5)\end{array}$ & $\begin{array}{l}0 \\
(7)\end{array}$ \\
\hline Forecast errors & $\begin{array}{l}18^{*} \\
(11)\end{array}$ & $\begin{array}{l}-1 \\
(12)\end{array}$ & $\begin{array}{l}32^{*} \\
(18)\end{array}$ & $\begin{array}{l}16 \\
(24)\end{array}$ & $\begin{array}{l}-0 \\
(16)\end{array}$ & $\begin{array}{l}25 \\
(47)\end{array}$ & $\begin{array}{c}0 \\
(16)\end{array}$ & $\begin{array}{c}1 \\
(16)\end{array}$ & $\begin{array}{c}1 \\
(15)\end{array}$ \\
\hline \multicolumn{10}{|l|}{ СОМ-СОМмIт } \\
\hline Forecast & $\begin{array}{c}16^{* *} \\
(7)\end{array}$ & $\begin{array}{l}14^{*} \\
(7)\end{array}$ & $\begin{array}{l}18 \\
(11)\end{array}$ & $\begin{array}{c}4 \\
(10)\end{array}$ & $\begin{array}{c}2 \\
(10)\end{array}$ & $\begin{array}{l}-1 \\
(17)\end{array}$ & $\begin{array}{l}4 \\
(5)\end{array}$ & $\begin{array}{l}2 \\
(6)\end{array}$ & $\begin{array}{l}7 \\
(7)\end{array}$ \\
\hline Forecast errors & $\begin{array}{l}17 \\
(12)\end{array}$ & $\begin{array}{c}7 \\
(14)\end{array}$ & $\begin{array}{l}22 \\
(18)\end{array}$ & $\begin{array}{l}15 \\
(24)\end{array}$ & $\begin{array}{l}-16 \\
(19)\end{array}$ & $\begin{array}{c}3 \\
(39)\end{array}$ & $\begin{array}{l}16 \\
(17)\end{array}$ & $\begin{array}{l}18 \\
(17)\end{array}$ & $\begin{array}{l}18 \\
(17)\end{array}$ \\
\hline
\end{tabular}

Notes. Panel A provides cumulative impulse responses (CIRFs) to an expansionary monetary policy surprise (associated with interest rate response to a $+100 \mathrm{bps}$ demand impulse) for the first two periods. CIRFs are constructed from the estimated equations (6)-(7). Standard errors (in parentheses) and confidence intervals are based on 1000 bootstrap simulations; ***, **, and * denote significant values at 1\%, 5\%, and 10\% confidence levels. Columns (1)-(3) provide CIRFs for forecasts and forecast errors for individual price, $p_{j t}^{*}$, estimated for all subjects (column 1), Top3 subjects (column 2), and Bottom3 subjects (column 3). Columns (4)-(6) provide the results for individual expenditures, $\bar{v}_{i t}$, and columns (7)-(9) provide the results for the interest rate. Panel B provides treatment effects, the differences between CIRFs for Treatment experiments (constructed from the estimated equation 8) and CIRFs for the Control experiment. 
Table 4: Aggregate responses

\begin{tabular}{|c|c|c|c|c|c|c|}
\hline \multirow[b]{2}{*}{ Experiment } & \multicolumn{3}{|c|}{ Demand shock } & \multicolumn{3}{|c|}{ Monetary surprise (easing) } \\
\hline & Inflation & Output & Int rate & Inflation & Output & Int rate \\
\hline \multicolumn{7}{|c|}{ Panel A: Control experiment } \\
\hline periods $0-1$ & $\begin{array}{c}65^{* \star *} \\
(7) \\
96^{* * *} \\
(30)\end{array}$ & $\begin{array}{l}64^{* * *} \\
(10) \\
25 \\
(28)\end{array}$ & $\begin{array}{c}76^{* * *} \\
(12) \\
172^{* * *} \\
(44)\end{array}$ & $\begin{array}{c}22^{* * *} \\
(8) \\
42^{* * *} \\
(16)\end{array}$ & $\begin{array}{l}44^{* * *} \\
(10) \\
64^{* * *} \\
(15)\end{array}$ & $\begin{array}{c}-66^{* * *} \\
(12) \\
-124^{* * *} \\
(25)\end{array}$ \\
\hline \multicolumn{7}{|c|}{ Panel B: Treatment effects (Treatment minus Control) } \\
\hline \multicolumn{7}{|l|}{ COM-BACK } \\
\hline periods $0-1$ & $\begin{array}{l}-8 \\
(11)\end{array}$ & $\begin{array}{l}-12 \\
(16)\end{array}$ & $\begin{array}{l}-23 \\
(18)\end{array}$ & $\begin{array}{c}6 \\
(11)\end{array}$ & $\begin{array}{l}-1 \\
(15)\end{array}$ & $\begin{array}{l}14 \\
(17)\end{array}$ \\
\hline periods $0-9$ & $\begin{array}{l}-50 \\
(35)\end{array}$ & $\begin{array}{l}36 \\
(35)\end{array}$ & $\begin{array}{c}-118^{* *} \\
(51)\end{array}$ & $\begin{array}{l}-10 \\
(18)\end{array}$ & $\begin{array}{l}-26 \\
(18)\end{array}$ & $\begin{array}{l}61^{* *} \\
(29)\end{array}$ \\
\hline \multicolumn{7}{|l|}{ adjusted for int rate } \\
\hline periods $0-1$ & $\begin{array}{l}-16 \\
(13)\end{array}$ & $\begin{array}{l}-27 \\
(22)\end{array}$ & $\begin{array}{l}-0^{* * *} \\
(0)\end{array}$ & $\begin{array}{l}10 \\
(13)\end{array}$ & $\begin{array}{c}7 \\
(18)\end{array}$ & $\begin{array}{l}0^{* * *} \\
(0)\end{array}$ \\
\hline \multirow[t]{2}{*}{ periods $0-9$} & $-91^{*}$ & -27 & $-0^{*}$ & 10 & 4 & $-0^{* *}$ \\
\hline & $(43)$ & $(47)$ & (0) & (15) & (17) & $(0)$ \\
\hline \multicolumn{7}{|l|}{ COM-FWD } \\
\hline \multirow[t]{2}{*}{ periods $0-1$} & -3 & -4 & 6 & -7 & 2 & 1 \\
\hline & (10) & (14) & (16) & (10) & (13) & (15) \\
\hline \multirow[t]{2}{*}{ periods $0-9$} & -12 & 22 & -34 & -24 & -8 & 41 \\
\hline & (33) & (34) & (51) & (17) & (18) & (28) \\
\hline \multicolumn{7}{|l|}{ adjusted for int rate } \\
\hline \multirow[t]{2}{*}{ periods $0-1$} & -1 & 0 & 0 & -8 & 1 & $0^{* * *}$ \\
\hline & (12) & (18) & (0) & (12) & (17) & (0) \\
\hline \multirow[t]{2}{*}{ periods $0-9$} & -23 & 4 & $0^{* * *}$ & -11 & 11 & $0^{* * *}$ \\
\hline & (37) & (44) & (0) & (16) & (19) & (0) \\
\hline \multicolumn{7}{|l|}{ СOM-СОМMIT } \\
\hline \multirow[t]{2}{*}{ periods $0-1$} & -7 & -12 & -15 & -1 & 2 & 16 \\
\hline & (10) & (15) & (18) & (11) & (14) & (17) \\
\hline \multirow[t]{2}{*}{ periods $0-9$} & -46 & -33 & -75 & -15 & 17 & $66^{* *}$ \\
\hline & (35) & (48) & (53) & (18) & (25) & (30) \\
\hline \multicolumn{7}{|l|}{ adjusted for int rate } \\
\hline \multirow{2}{*}{ periods $0-1$} & -12 & -22 & $0^{* * *}$ & 4 & 12 & $-0^{* * *}$ \\
\hline & (13) & (20) & (0) & (12) & (18) & (0) \\
\hline \multirow[t]{2}{*}{ periods $0-9$} & $-72^{*}$ & -72 & $0^{* *}$ & 6 & $50^{* *}$ & $-0^{* *}$ \\
\hline & (41) & (57) & (0) & (14) & (25) & (0) \\
\hline
\end{tabular}

Notes. Panel A provides cumulative impulse responses (CIRFs) to a +100 bps demand impulse and the associated expansionary monetary policy surprise for the first two periods ("periods $0-1$ ") and the first 10 periods ("periods 0-9"). CIRFs are constructed from the estimated equations (6)-(7). Standard errors (in parentheses) and confidence intervals are based on 1000 bootstrap simulations; ${ }^{* * *},{ }^{* *}$, and ${ }^{*}$ denote significant values at $1 \%, 5 \%$, and $10 \%$ confidence levels. Columns (1)-(3) provide CIRFs for inflation $\left(\pi_{t}\right)$, output $\left(y_{t}\right)$, and interest rate $\left(i_{t}\right)$ conditional on demand shocks; and columns (4)-(6) provide the results conditional on expansionary monetary policy surprises. Panel B provides treatment effects, the differences between CIRFs for Treatment experiments (constructed from the estimated equation 8) and CIRFs for the Control experiment. Shaded areas provide counterfactual treatment effects adjusted for the change in interest rates. 
Figure 1: Impulse responses, control experiment

\section{Panel A. +100 bps demand impulse}
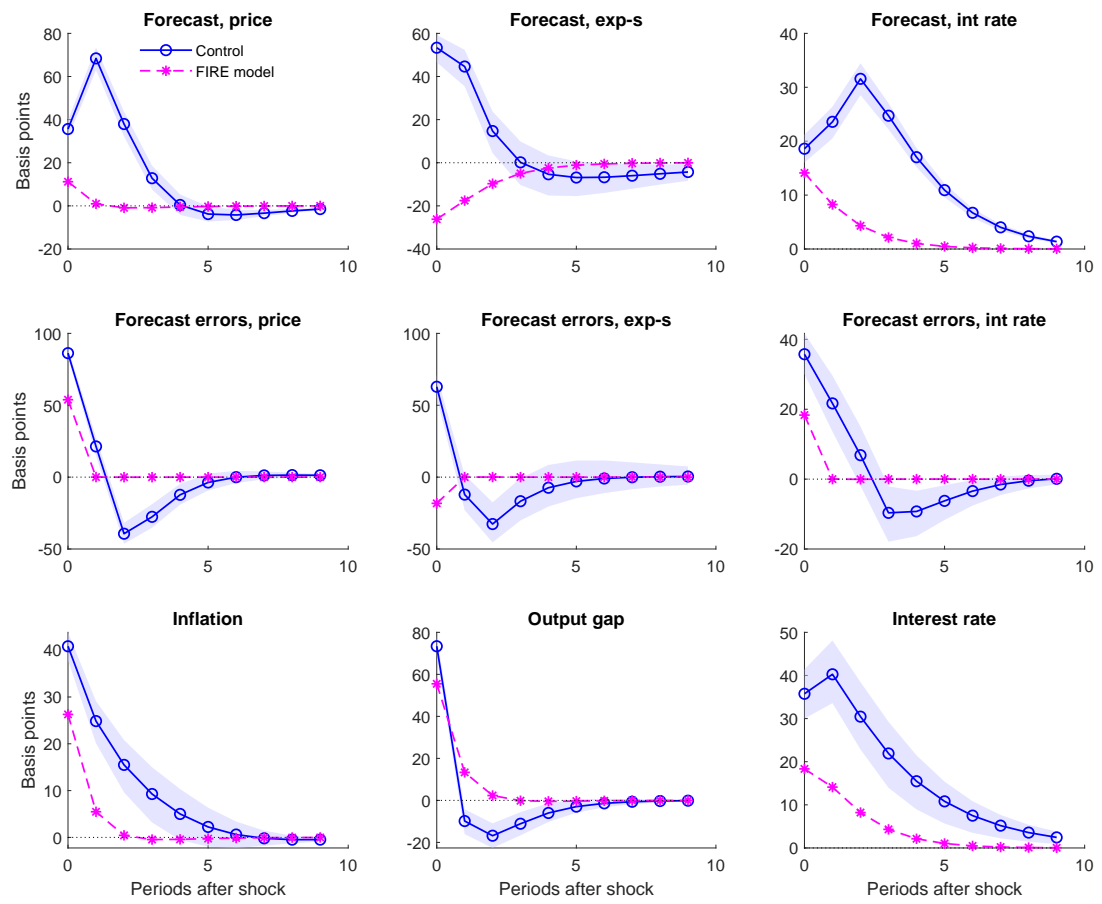

Panel B. Expansionary monetary policy surprise
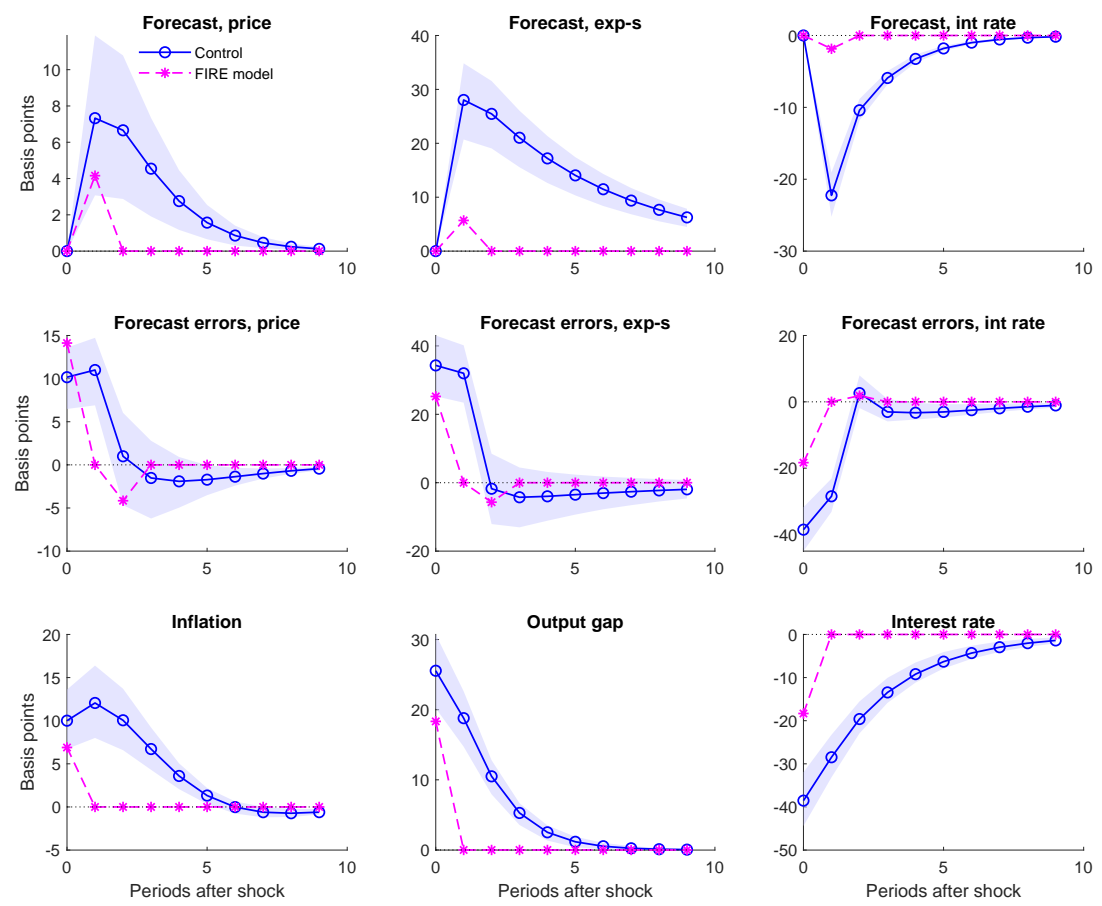

Notes. Impulse response functions (IRFs) in the control experiment are constructed from the estimated equations (6)-(8). Shaded areas outline one-standard-deviation bands based on 1000 bootstrap simulations. IRFs in the model are derived from simulations of equilibrium under full-information rational expectations (FIRE model). 
Figure 2: Responses to shocks across subjects, control experiment
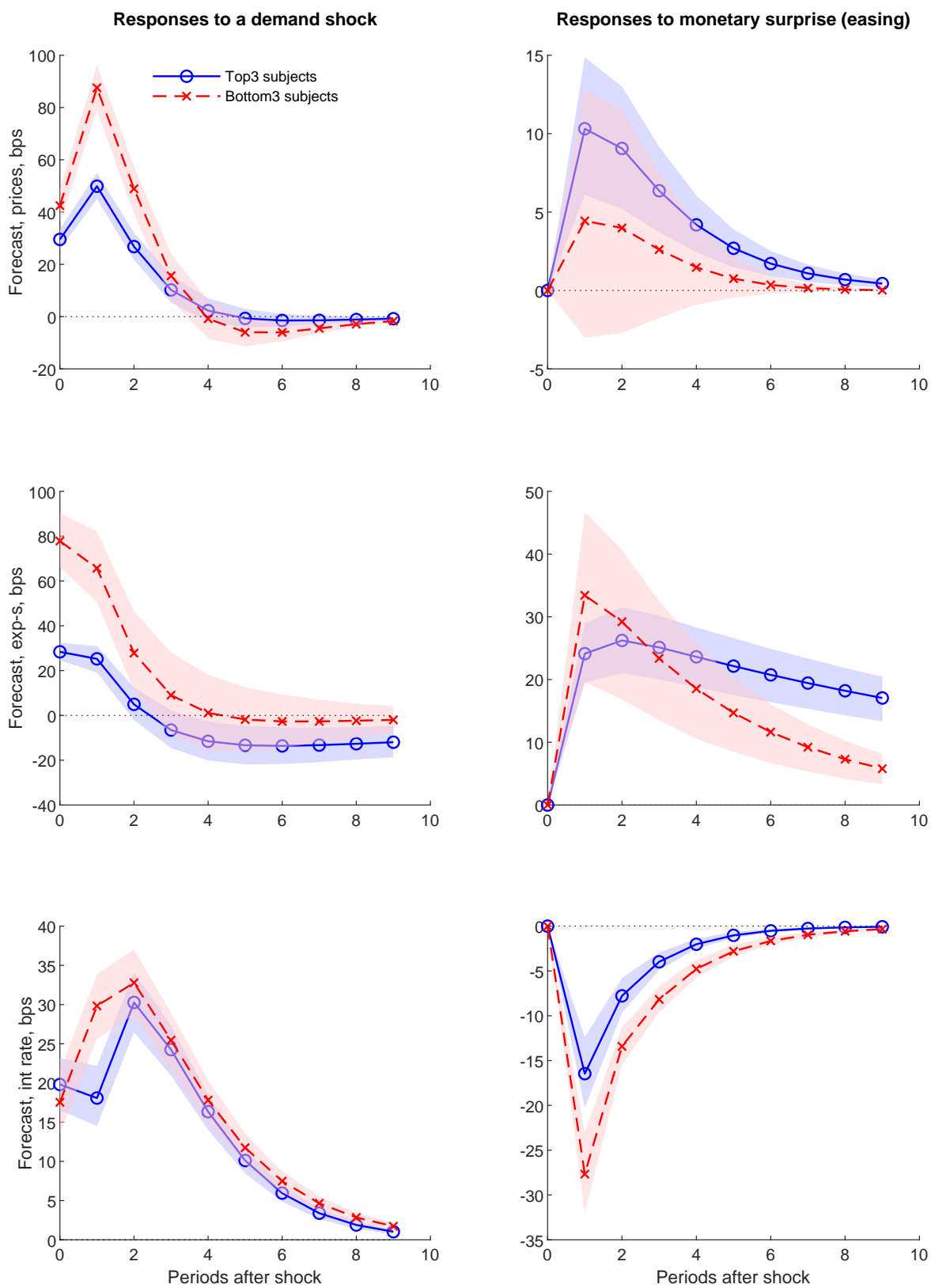

Notes. Figure provides impulse responses (IRFs) to a +100 bps demand impulse (left panels) and the associated expansionary monetary policy surprise (right panels) in the control experiment. IRFs are constructed from the estimated equations (6)-(8), using observations for Top3 subjects (blue) and Bottom3 subjects (red). Shaded areas outline one-standard-deviation bands based on 1000 bootstrap simulations. The top row provides IRFs for forecasts of individual price, $E_{j t} p_{j t+1}^{*}$; the middle row provides forecasts of individual expenditures, $E_{i t} \bar{v}_{i t+1}$; and the bottom row provides forecasts of interest rate, $E_{i t} i_{t+1}$. 
Figure 3: Forecast responses in experiments

\section{Panel A. +100 bps demand impulse}
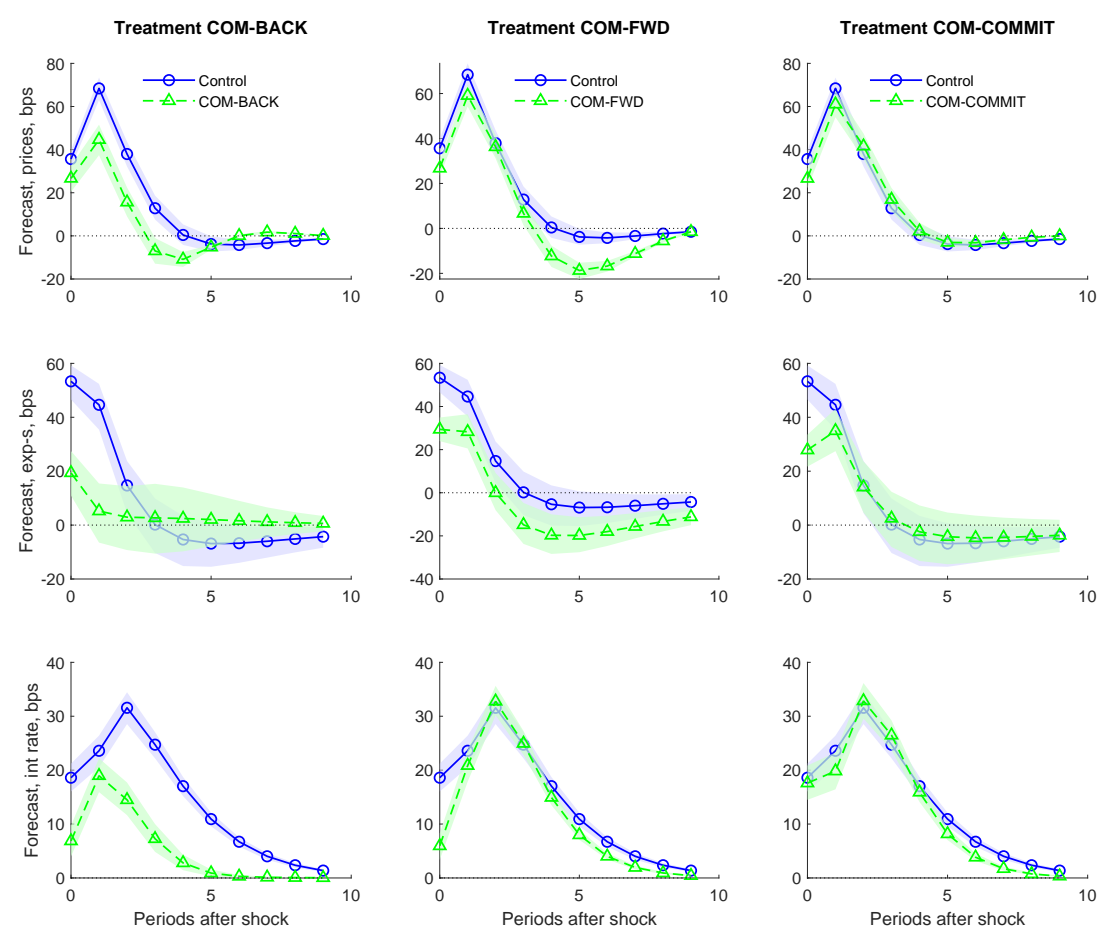

Panel B. Expansionary monetary policy surprise
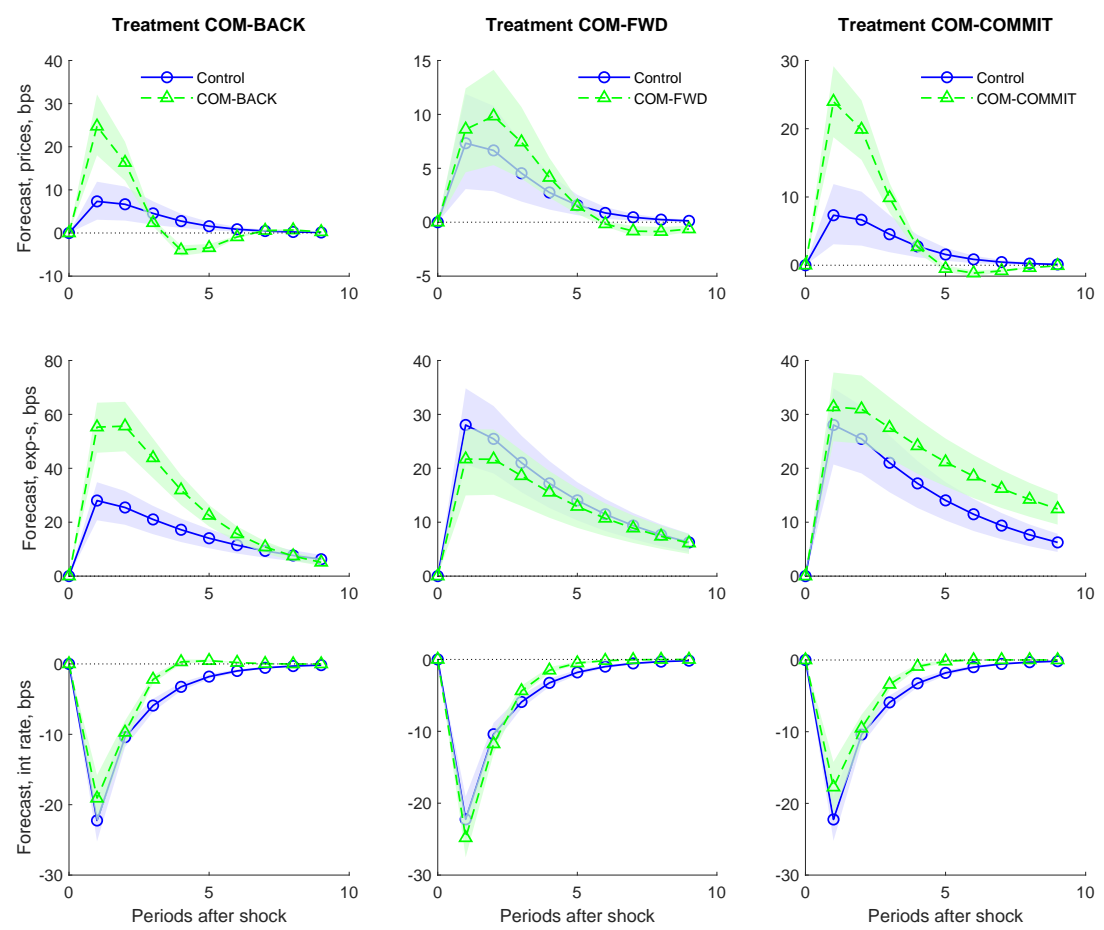

Notes. Figure provides impulse responses (IRFs) to a +100 bps demand impulse and an expansionary monetary surprise. Shaded areas outline one-standard-deviation bands based on 1000 bootstrap simulations. In each panel, the top row provides IRFs for forecasts of individual price, $E_{j t} p_{j t+1}^{*}$; the middle row provides forecasts of individual expenditures, $E_{i t} \bar{v}_{i t+1}$; and the bottom row provides forecasts of interest rate, $E_{i t} i_{t+1}$. Columns span treatment experiments: COM-BACK (left), COM-FWD (middle), and COMCOMMIT (right). 
Figure 4: Aggregate responses in experiments

Panel A. +100 bps demand impulse
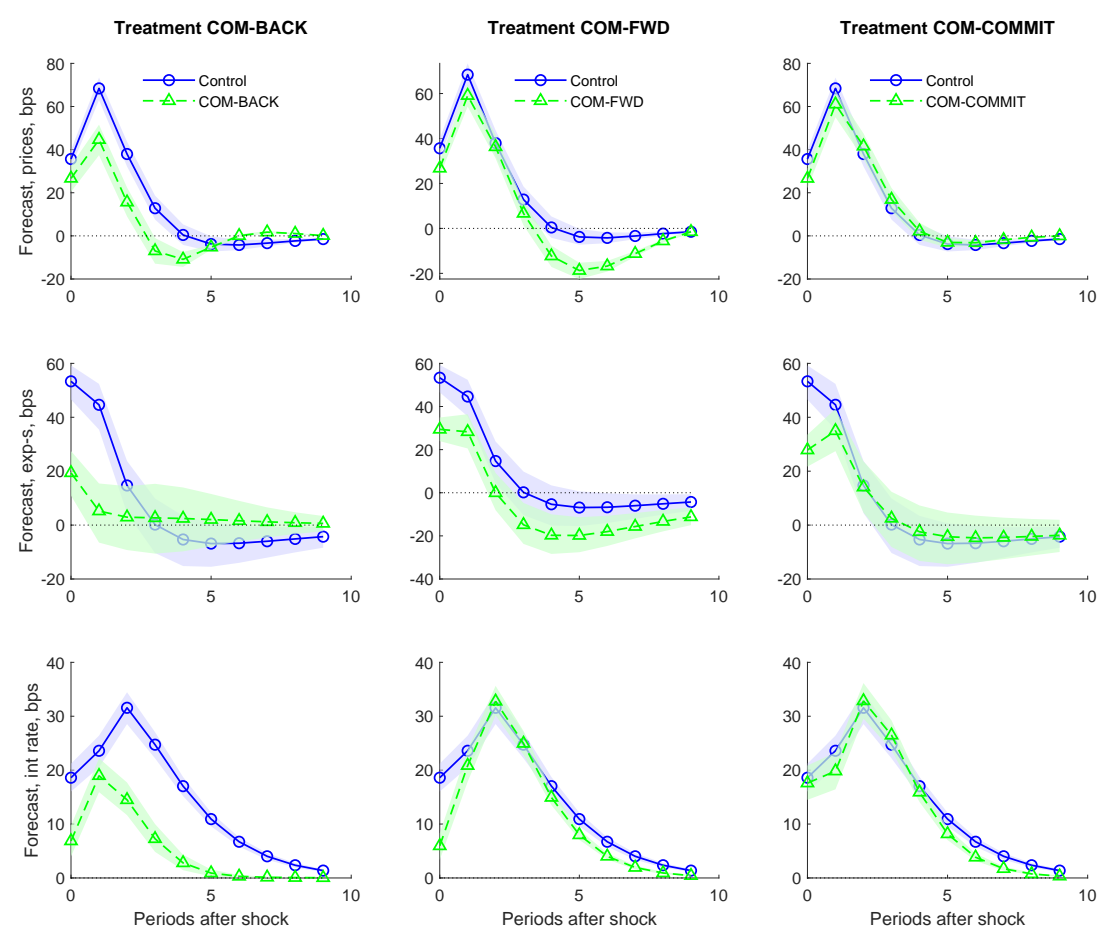

Panel B. Expansionary monetary policy surprise
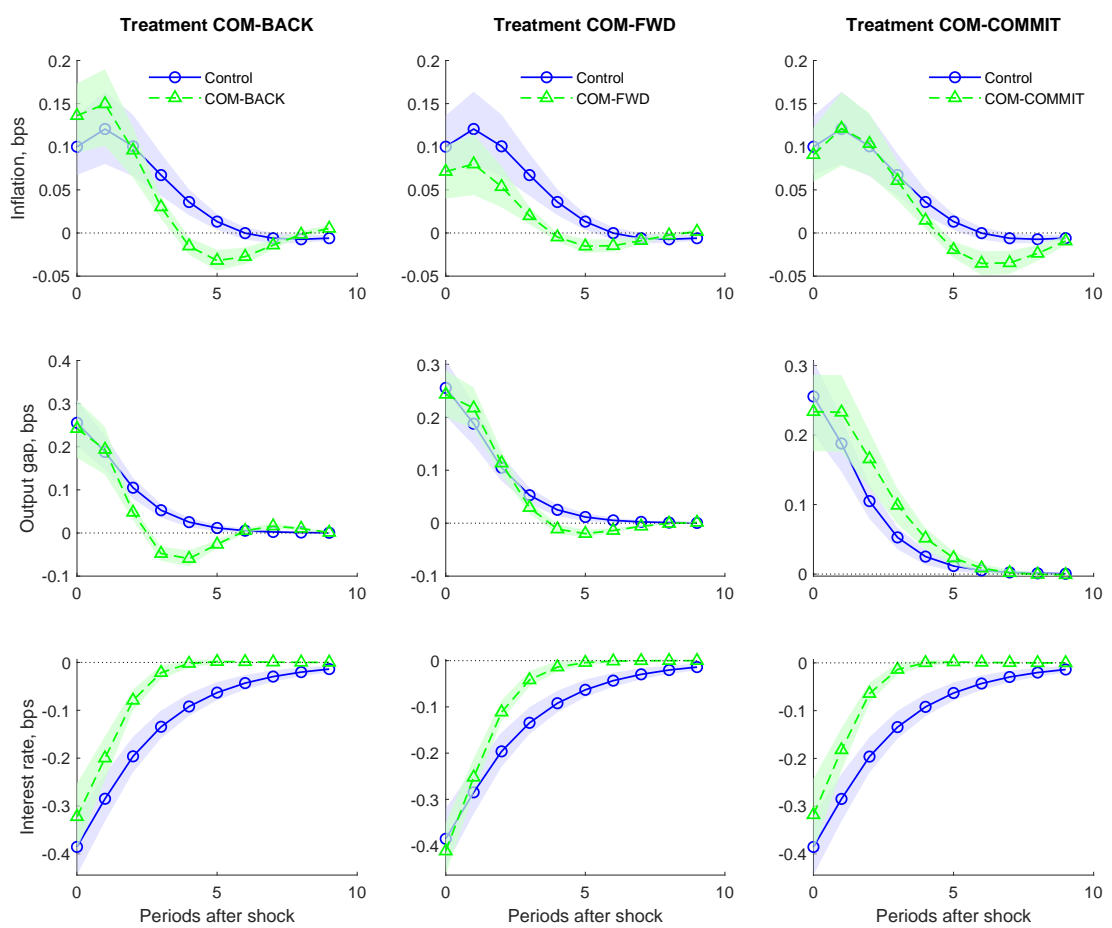

Notes. Figure provides impulse responses (IRFs) to a +100 bps demand impulse and an expansionary monetary surprise. Shaded areas outline one-standard-deviation bands based on 1000 bootstrap simulations. In each panel, the top row provides IRFs for inflation $\left(\pi_{t}\right)$; the middle row provides output $\left(y_{t}\right)$; and the bottom row provides interest rate $\left(i_{t}\right)$. Columns span treatment experiments: COM-BACK (left), COMFWD (middle), and COM-COMMIT (right). 